\title{
Plastics in robots: a degradation study of a humanoid skin mask made of soft urethane elastomer
}

\author{
Anna Micheluz' ${ }^{1}$ Eva Mariasole Angelin 1,2, Julia Sawitzki and Marisa Pamplona ${ }^{1 *}$ (i)
}

\begin{abstract}
Understanding the degradation of plastic materials is a big challenge for curators, conservators and conservation scientists in museums worldwide aiming to preserve their collections due to the variety of formulations of synthetic polymers and pigments. The conservation of polyurethane (PUR) based objects is challenging because they can suffer from extensive degradation. Particularly PUR elastomers can degrade shortly after their production, as occurred to the mask of the Japanese robot SAYA, which within 8 years suffered from two large tears, discoloration and stickiness. This research aims at studying the degradation phenomena of the androids'synthetic skin. Better knowledge of the chemical composition of the mask and the chemical and physical decay will contribute to planning a suitable stabilization treatment. Within a multi-analytical approach, colorimetric and microscopic investigations highlighted discolored areas, which showed further color changes within a five months monitoring campaign, confirming the instability of the material likely due to ongoing degradation. Raman microscopy allowed the identification of Pigment White 6 (titanium dioxide $\mathrm{TiO}_{2}$ ) in the anatase form, known to promote the photosensitivity of PUR substrates towards ultraviolet (UV) light. Attenuated total reflectance Fourier transform infrared (ATR-FTIR) spectroscopy identified the PUR composition of the mask, the presence of phthalates as plasticizers and suggested the formation of quinone chromophores in the polymer structure as a result of photo-oxidation, possibly responsible for the mask yellowing. Evolved gas analysis-mass spectrometry (EGA-MS) and double-shot-gas chromatography/mass spectrometry (TD/PyGC/MS) analyses support the characterization of the formulation of the mask as being made of methylene diphenyl diisocyanate (MDI) PUR ether elastomer. Plasticizers in high concentration, mainly diisononyl phthalate (DINP) and bis(2-ethylhexyl)phthalate (DEHP), and the UV stabilizer Tinuvin 328 were also detected. In addition, the presence of styrene-acrylonitrile (SAN) could also contribute to the mask's chemical instability. More amount of UV stabilizer and phthalates were detected at the surface (contributing to its stickiness) than in the inner core. The degradation of the mask results from the light susceptibility of MDI PUR ether and SAN, as well as the higher photochemical activity of anatase. The mask was transferred on to a mannequin and placed in the storage area to prevent light exposure and photo-oxidation. As loose edges had to be stabilized, tests were conducted and adhesive stripes glued with a PUR dispersion were selected for keeping the head's shape. The novelty of this study is the implementation of conservation science on the study of androids with PUR elastomeric components in robotic collections, which are becoming increasingly popular in technical museums, however still seldomly studied.
\end{abstract}

Keywords: Humanoid robot, Urethane elastomer (PUR), Natural aging, Yellowing, Stickiness, Raman microscopy, ATRFTIR, EGA-MS, TD/Py-GC/MS, Preventive conservation

\footnotetext{
*Correspondence: m.pamplona@deutsches-museum.de

${ }^{1}$ Conservation Science Department, Deutsches Museum, Museumsinsel

1, 80538 Munich, Germany

Full list of author information is available at the end of the article
}

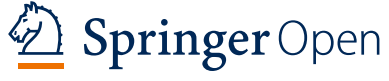

(c) The Author(s) 2022. Open Access This article is licensed under a Creative Commons Attribution 4.0 International License, which permits use, sharing, adaptation, distribution and reproduction in any medium or format, as long as you give appropriate credit to the original author(s) and the source, provide a link to the Creative Commons licence, and indicate if changes were made. The images or other third party material in this article are included in the article's Creative Commons licence, unless indicated otherwise in a credit line to the material. If material is not included in the article's Creative Commons licence and your intended use is not permitted by statutory regulation or exceeds the permitted use, you will need to obtain permission directly from the copyright holder. To view a copy of this licence, visit http://creativecommons.org/licenses/by/4.0/. The Creative Commons Public Domain Dedication waiver (http://creativeco mmons.org/publicdomain/zero/1.0/) applies to the data made available in this article, unless otherwise stated in a credit line to the data. 


\section{Introduction}

Since the 1990s, technology research has led to the development of robots increasingly similar to humans. The studies of this type of robot imply investigating the possible mechanisms, intelligence, and/or functions required for an effective interaction with humans, such as facial expression. Therefore, several robots with an anthropomorphic face capable of mimicking emotions, e.g. surprise, fear, disgust, anger, happiness and sadness, were developed [1-6]. Investigations of the biomechanics of the human face permitted the reproduction of basic facial movements, controlled by several actuators with mechanical drives or smart systems [6]. The first robotic faces were composed of: a mechanical structure with actuators, a skull frame often made of fibre-reinforced plastic (FRP) and facial skin [2-4]. The similarity of robot's facial expressions with human beings depends on the number and locations of control points on the facial skin for deformation. Therefore, the artificial mask needs to be deformable, soft and similar to the human skin texture. Soft polyurethane (PUR) or synthetic silicone rubber $[2,4,6-8]$ were usually used to reproduce the humanoid masks created by mould technology. The production, often used in art and for the reproduction of special cinematic effects, follows a series of moulding processes, which consist of: (i) production of a human face mould; (ii) injection of an elastomer in the mould; (iii) release of the skin and finish the manufacture by trimming, painting and making up $[4,5]$. PUR elastomers are formed by polymerization of diisocyanate (either aromatic or aliphatic), polyester or polyether polyols (macrodiols) and chain extenders (typically small-molecule diol or a diamine), which are characterized by an alternation of hard (diisocyanate-chain extender sequence) and soft (macrodiol sequence) segments $[9,10]$. Their casting procedure consists of mixing two low viscous liquid components under a specific ratio, generally expressed by the supplier, which cures at room temperature. The two components are often a polyol mixture and an isocyanate. Based on the required softness, a certain quantity of plasticizer can be also added $[9,11]$. Other additives, such as UV absorbers, antioxidants and pigments, are introduced into the polyol part during the beginning of the moulding [11].

Objects made of PUR, together with those made of cellulose nitrate, cellulose acetate and polyvinylchloride (PVC), tend to be more susceptible to degradation than other plastic objects in museum collections [12-14]. Several studies were conducted to understand the aging of PUR foams [12-18] or PUR coatings [19, 20], which alterations depend mainly on the ether or ester composition of the polymer. PUR ether polymers are more sensitive to oxidation, which causes discoloration and loss of mechanical properties, while PUR ester polymers degrade mainly by hydrolysis, caused by exposure to moisture, heat and light, and lead to chain scission of the polymer and its crumbling $[10,12,21]$. However, only few studies were dedicated to objects made of PUR elastomer and their degradation. An example is the design object Soft Vase (1994) of the Dutch designer Hella Jongerius made by PUR ester elastomer internally plasticized with 1,4-butanediol (chain extenders), which presented only mechanical damages [9]. Other investigated objects were the works of art of the series Stage Evidence of the Italian artist Loris Cecchini. Capanna et al. [22] have reported mechanical damages, loss of elasticity, weeping of liquids and stickiness for Stage Evidence 2002 (fotocopiatrice), while de Groot et al. [9] and Lazzari et al. [23] have reported also yellowing for Finestre II (2000) and Stage Evidence (1999), respectively. The objects were identified as PUR ester elastomer [9, 22] and PUR ether elastomer [23] with a high content of phthalates used as plasticizers. A similar degradation phenomenon found on the objects of Loris Cecchini was observed on the facial mask of the robot SAYA. ${ }^{1}$ The android was developed and built by Professor Hiroshi Kobayashi and his team from the Tokyo University of Science in 2009, including the facial skin made of soft PUR elastomer [2]. The prototype was tested as a telecommunication interface with humans and served initially as a receptionist and, later on, as an English teacher in Japanese elementary schools [24]. SAYA was loaned to the Deutsches Museum (Munich, Germany) in 2017 to be part of the future permanent robotics' exhibition. However, already in 2017 the facial mask was severely degraded. Besides the allover stickiness, a localized discoloration of the PUR elastomer was visible, changing from a human-looking skin to spotty colored patterns. Moreover, two large tears located around the neck and close to the left shoulder compromised the mask's integrity (Additional file 1: Fig. S1). Their development is likely associated with tensile stresses, deriving from the head movements during function and/or tilted back resting position.

The investigation aimed to characterize the composition of the PUR mask; understand its degradation phenomena, and suggest measures for minimizing its degradation.

Within this study colorimetry, microscopy, scanning electron microscopy-energy dispersive X-ray (SEMEDX), Raman microscopy ( $\mu$-Raman), attenuated total

\footnotetext{
1 The name Saya has the following two meanings: 1) "SAYA" is originally written in Chinese character (KANJI) meaning "bloom in the field"; 2) Saya means "me" in Malayan. The Japanese researcher team used it to mean that the robot has an ego (Prof. Takuya Hashimoto, personal communication, November 2, 2020).
} 


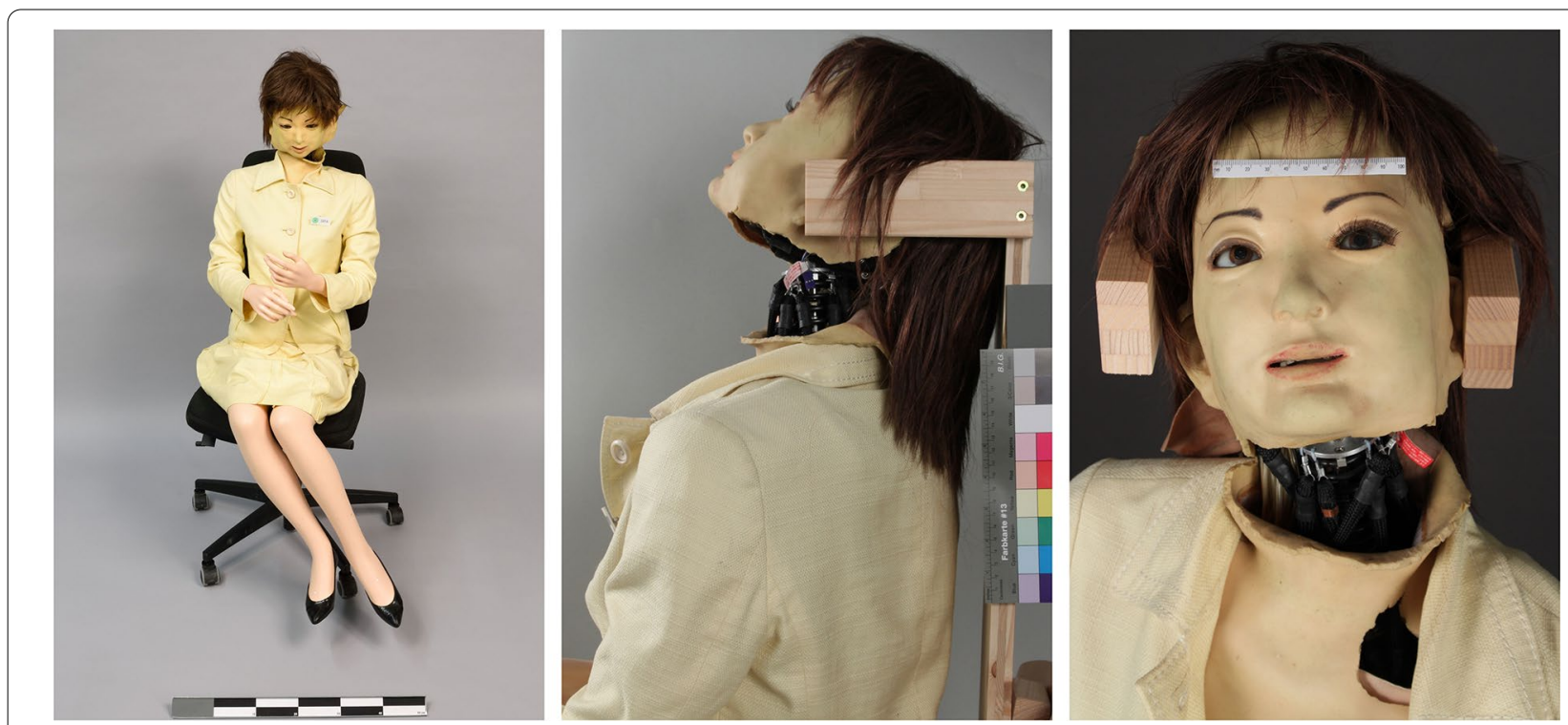

Fig. 1 Humanoid SAYA prototype after arrival at the Deutsches Museum, November 2017 (Ph. A. Kaufmann)

reflectance Fourier transform infrared spectroscopy (ATR-FTIR), evolved gas analysis-mass spectrometry (EGA-MS) followed by double-shot-gas chromatography/mass spectrometry (TD/Py-GC/MS) were employed. Based on the material analysis, a new support (mannequin) was chosen, and the effectiveness of gluing stripes for stabilizing the tears was assessed. Thanks to the integration of the information gathered from the multi-technique approach, new insights into the chemical composition of the PUR elastomeric mask and its degradation were achieved, helping to suggest preventive and active conservation measures for its long-term preservation at the Deutsches Museum.

\section{Materials and methods \\ The SAYA mask}

The humanoid robot SAYA's mask is made of a soft PUR elastomer, HITOHADA GEL@ $\odot$ by EXSEAL CO., LTD (Prof. Takuya Hashimoto, personal communication, November 5, 2019). The elastomeric skin was severely degraded when it arrived at the Deutsches Museum in November 2017 (Fig. 1).

To prepare the future permanent exhibition, several meetings with the robotic curators started in March 2019. Unfortunately, due to the poor condition state of the mask, it was decided to replace it. A diagnostic campaign started on SAYA's mask to understand its decay and protect it in the storage area. Therefore, the skin was transferred onto a new inert mannequin made of polypropylene (PP) with a similar shape to the robot's head (Fig. 2). While removing the mask, it was observed that the actuators located inside the skull could control the facial movements through metal connections between themselves and the inner surface of the mask. Mask and skull were secured via velcros (e.g. cheeks, top of the head and ears).

Furthermore, the external surface of the mask displayed an inhomogenous coloration: a pale pink color around the eyes, ears, band on the top of the head, zip in the back, neck and a part of the chest; and yellow on the rest (Additional file 1: Fig. S1). The location of those color regions on the different parts of the mask could not be associated with a specific degradation trend.

Two distinct color profiles were observed on the mask's edges (Fig. 3): yellow | pale pink core | yellow (section a); pale pink | glue (section b) corresponding to regions exposed to oxygen from the outside and with a glue in the inside. Samples from the yellow surface and the pale pink core were taken from section a for investigating the deterioration.

The glue (Fig. 3, section b) helped fix the metallic connections between the mask and the skull, as well as the adhesion between the mask and a velcro tape. Microsamples of the glue and of the skull were taken for analysis.

\section{Colorimetry}

The color measurement on the mask's surface was conducted with the portable Konica Minolta CM-700d Spectrocolorimeter (Minolta Co. Ltd., Japan) in May 2019. The measurement campaign was repeated 5 months later (October 2019) to monitor possible changes or color shifts. The following parameters were used for the 

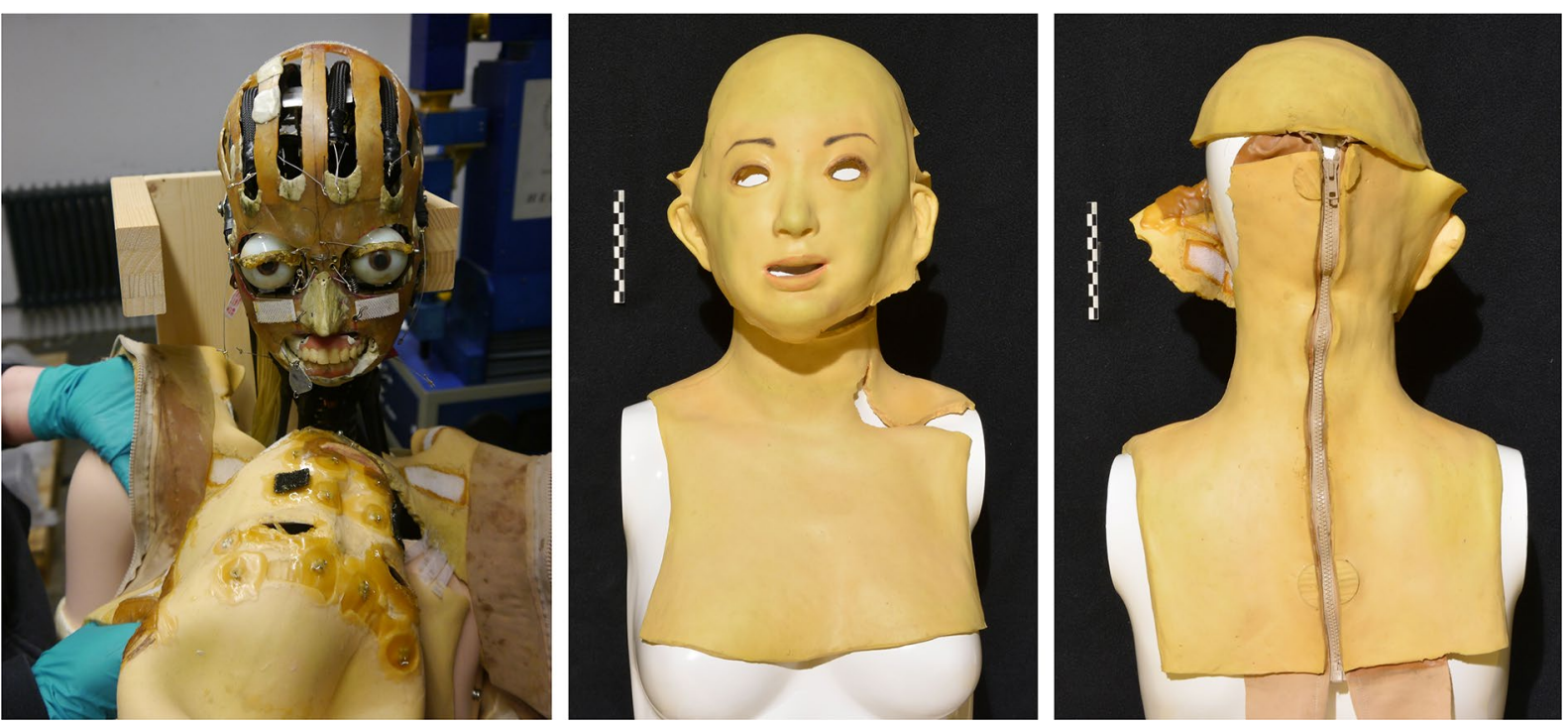

Fig. 2 Removal of the elastomer PUR mask and its transfer to the PP mannequin. (May 2019)

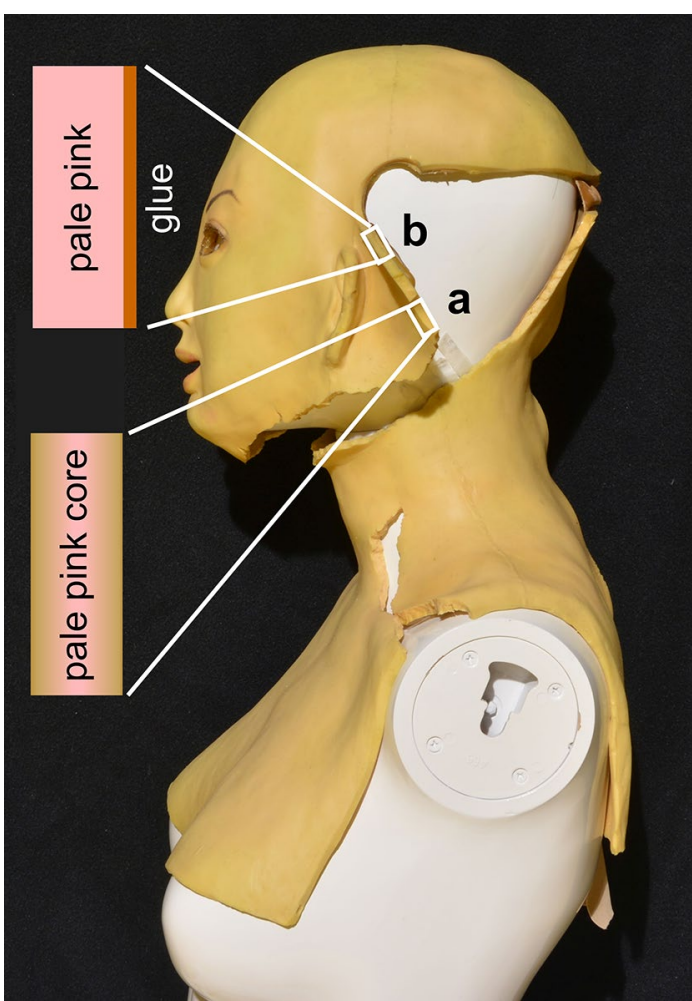

Fig. 3 Schematic color profiles (a, $\mathbf{b})$ observed on the edges of SAYA's mask (May 2019)

measurements: spectral range $400-700 \mathrm{~nm}$ with a wavelength pitch of $10 \mathrm{~nm}, \mathrm{~d} / 8^{\circ}$ geometry, $\mathrm{SCI}$ mode, $10^{\circ} \mathrm{col}-$ orimetric observer (CIE 1964), D65 standard illuminant and measurement area of $3 \mathrm{~mm}$ in diameter. In addition, measurement points of the mask's external surface were selected in both the pale pink and yellowed regions, recording two replicas for each point. The color difference was calculated as the coefficient $\Delta \mathrm{E}$ using the of CIEL"a*b* color space ( $\mathrm{L}^{*}$ as a parameter for brightness between 100 for white and 0 for black, while $a^{*}$ and $b^{*}$ are the chromaticity coordinates) and the mathematical formula of CIEDE $1976\left(\Delta \mathrm{E}_{\mathrm{a}, \mathrm{b}}^{*}\right)$ [25]:

$$
\Delta \mathrm{E}_{\mathrm{a}, \mathrm{b}}^{*}=\left(\mathrm{L}_{2}^{*}-\mathrm{L}_{1}^{*}\right)^{2}+\left(\mathrm{a}_{2}^{*}-\mathrm{a}_{1}^{*}\right)^{2}+\left(\mathrm{b}_{2}^{*}-\mathrm{b}_{1}^{*}\right)^{2} /^{0,5}
$$

This formula was applied to calculate both the color change between non degraded (pale pink, subscript 1) and degraded (yellow, subscript 2) areas and possible color variations in correspondence of these two areas over the monitoring period (May 2019, subscript 1; October 2019, subscript 2). A positive difference of $\Delta \mathrm{a}^{*}$ and $\Delta b^{*}$ describes red and yellow shifts, while a negative difference of $\Delta \mathrm{a}^{*}$ and $\Delta \mathrm{b}^{*}$ describes green and blue shifts $[19,26]$.

\section{Microscopic and scanning electron microscopy-energy} dispersive X-ray spectrometry (SEM-EDX) investigations Visual differences between the yellowed surface and pale pink core were examined under a digital microscope (Keyence VHX-1000) equipped with a 5-50× objective lens and a scanning electron microscope Phenom ProX, version G3 (Phenomworld, now ThermoFisher), low vacuum, Ce-hexahybrid cathode. EDX-analysis were performed with $15 \mathrm{kV}$, point beam current and $90 \mathrm{~s}$, 
standardless ZAF quantification. The sample was analyzed without any preliminary preparation.

\section{Raman microscopy ( $\mu$-Raman)}

For the identification of pigment(s), the PUR sample was analyzed superficially and in cross-section by $\mu$-Raman spectroscopy. The sample was placed onto glass slides on the stage of an Olympus BXFM-ILHS microscope coupled to a Jobin Yvon LabRam 300 confocal Raman spectrometer. The $\mu$-Raman study was carried out using $785 \mathrm{~nm}$ line of diode laser $(100-\mathrm{mW})$, for the Raman excitation. The apparatus included an air-cooled multichannel CCD detector. Gratings of 600 groves $/ \mathrm{mm}$ were used to collect spectra between 100 and $1000 \mathrm{~cm}^{-1}$. The system was calibrated by using the $520.7 \mathrm{~cm}^{-1}$ band of a standard silicon $\left(\begin{array}{lll}1 & 0 & 0\end{array}\right)$ wafer. The confocal pinhole was maintained at a minimum aperture $(200 \mu \mathrm{m})$ to reduce the thickness of the focal plane. Integration time and accumulations were noted to achieve an acceptable $\mathrm{s} / \mathrm{n}$ ratio. The laser beam was focused on the sample by a $\times 100$ objective lens to give a spot size of approximately $1 \mu \mathrm{m}$. The laser power at the surface of the samples was controlled using neutral density filters (optical densities $0.3,0.6,1$ and 2). Spectra were recorded as an extended scan. Raman data analysis was performed using LabSpec 5 software (Horiba Jobin Yvon).

\section{Attenuated total reflectance Fourier transform infrared spectroscopy (ATR-FTIR)}

Infrared analyses of the yellow surface (Fig. 3a), the pale pink core and the glue (Fig. 3b) found on the reverse of the mask were performed with an Alpha FT-IR Spectrometer (Bruker) equipped with a diamond crystal. Infrared spectra were collected after 64 scans from 4000 to $400 \mathrm{~cm}^{-1}$ with a resolution of $4 \mathrm{~cm}^{-1}$, recording two replicas for each point. The interpretation of spectra was performed with the OPUS 7.2 software (Bruker). Bis(2ethylhexyl)phthalate (DEHP, Sigma Aldrich) was used as plasticizer reference material to perform a spectral comparison.

\section{Evolved gas analysis-mass spectrometry (EGA-MS)}

Evolved gas analyses of the yellow surface and the pale pink core were carried out using a Multi-shot Pyrolyzer EGA/PY-3030D (Frontier Lab.). Around $200 \mu \mathrm{g}$ of the sample were added directly into a stainless steel Ecocup sample holder (Frontier Lab.). The pyrolyzer temperature program varied from 100 to $700{ }^{\circ} \mathrm{C}$ (hold for $5 \mathrm{~min}$ ), increasing $20^{\circ} \mathrm{C} / \mathrm{min}$. The evolved gas was transferred directly into the 5977B MSD mass spectrometer (Agilent) through a deactivated and uncoated stainlesssteel transfer Frontier Ultra Alloy ${ }^{\circledR}$ EGA tube (UADTM 2.5N-2.5m-I.D. 0.15 mm, O.D. 0.47 mm, Frontier Lab.) maintained at $300{ }^{\circ} \mathrm{C}$ in the $7890 \mathrm{~B} \mathrm{GC}$ system oven (Agilent) with Helium as the carrier gas, a flow rate of $1.2 \mathrm{~mL} /$ $\mathrm{min}$ and a split ratio of 25:1. Ion detection was carried out in the $m / z$ range 25-550. The thermogram interpretation and the volatile compound identification were performed using a mass spectrum comparison and a selective ion curve extraction with the software and database F-Search 3.5.0 (Frontier Lab.) as well as literature data $[17,27]$.

\section{Double-shot-gas chromatography/mass spectrometry (TD-Py/GCMS)}

In order to collect more information about the volatile organic compounds and the polymeric composition, double-shot-GCMS (see instrumental details in the section above) was applied to measure ca. $200 \mu \mathrm{g}$ of the yellow surface and ca. $200 \mu \mathrm{g}$ of the pale pink core. The first step, thermal desorption (TD-GC/MS), was performed from $50{ }^{\circ} \mathrm{C}$ (hold for $2 \mathrm{~min}$ ) to $320{ }^{\circ} \mathrm{C}$ (hold for $3 \mathrm{~min}$ ) with an increasing ratio of $20{ }^{\circ} \mathrm{C} / \mathrm{min}$. At the beginning of the separation column, the focalization of the volatile compounds was assured by a cryo-trap maintained at $-180{ }^{\circ} \mathrm{C}$ with liquid nitrogen [28]. The second step, flash pyrolysis (Py-GC/MS), was conducted at $600{ }^{\circ} \mathrm{C}$ for 6 s. GC separation was performed using a Frontier UA5 capillary column (30 m-0.25F, $30 \mathrm{~m} \times 250 \mu \mathrm{m} \times 0.25 \mu \mathrm{m}$, Frontier Lab.), Helium as the carrier gas with a flow rate of $1.2 \mathrm{~mL} / \mathrm{min}$ and a split of 30:1. The injector temperature was set to $300^{\circ} \mathrm{C}$. The column temperature program was set from $40{ }^{\circ} \mathrm{C}$ (hold for $2 \mathrm{~min}$ ) with a heating rate of $20{ }^{\circ} \mathrm{C} / \mathrm{min}$ until $280{ }^{\circ} \mathrm{C}$ (hold for $5 \mathrm{~min}$ ). The ionization was EI positive mode at $70 \mathrm{eV}$, source temperature at $230{ }^{\circ} \mathrm{C}$, quadrupole at $150{ }^{\circ} \mathrm{C}$ and mass scanning range of 15 to $550 \mathrm{~m} / z$. Compound identification was performed using NIST MS Search 2.2 and F-Search 3.5.0 (Frontier Lab.) databases and literature data [17, 27, 29].

\section{Testing the effectiveness of gluing stripes for stabilizing the tears on the new mannequin}

In order to stabilize and minimize further deformations, an active conservation treatment was planned. It aimed to find suitable gluing stripes that can restabilize adhesion between the tears and connect the mask outward bent edges with the mannequin for keeping its original shape.

The gluing stripes consist of Japanese paper, which were tested with several adhesives. The ripped longfibred Japanese paper (100\% Kozo fibres, $12 \mathrm{~g} / \mathrm{m}^{2}$, Deffner \& Johann $\mathrm{GmbH}$ ), a material widely used in the conservation field [30-32], should allow a smoother transition between edges and provide sufficient strength due to the Kozo fibres length. The adhesives should be soluble in water to avoid the exposure of the PUR to harsh solvents and guarantee a long-term flexibility and elasticity 
Table 1 Chemical composition, properties and preparation of the adhesives

\begin{tabular}{|c|c|c|c|c|c|}
\hline Adhesive & Methocel A 15 LV & Tylose MH 300 & Tylose MH 1000 & $\begin{array}{l}\text { Polyurethane Dispersion } \\
\text { PU } 52\end{array}$ & Wheat starch paste \\
\hline Composition & Methylcellulose & $\begin{array}{l}\text { Methylhydroxy- } \\
\text { ethylcellulose }\end{array}$ & $\begin{array}{l}\text { Methylhydroxy-ethylcel- } \\
\text { lulose }\end{array}$ & $\begin{array}{l}\text { Aliphatic Polyester- } \\
\text { urethane }\end{array}$ & Starch \\
\hline Mass percentage & $5 \%$ & $5 \%$ & $5 \%$ & $\begin{array}{l}\text { Undiluted (38-40\% solid } \\
\text { content) }\end{array}$ & $10 \%$ \\
\hline Viscosity & $12-18 \mathrm{mPa} . \mathrm{s}$ & $300 \mathrm{mPa} . \mathrm{s}$ & $1000 \mathrm{mPa} . \mathrm{s}$ & 50-500 mPa.s & Min. 300 BU (Brabender Unit) \\
\hline Solvent & Distilled water & Distilled water & Distilled water & Dispersed in distilled water & Distilled water \\
\hline Long-term reversibility & Good & Good & Good & Poor & Good-mediocre \\
\hline
\end{tabular}

[33]; therefore, cellulose-based adhesives were tested [34]: (i) Methocel A 15 LV (Merck KGaA), (ii) Tylose MH 300 (Kremer Pigmente GmbH \& Co. KG), (iii) Tylose MH 1000 (Kremer Pigmente GmbH \& Co. KG), iv) wheat starch paste (Kremer Pigmente $\mathrm{GmbH} \&$ Co. KG). A synthetic polymer-based adhesive, the aqueous PUR dispersion with no free isocyanate groups PU 52 (Kremer Pigmente GmbH \& Co. KG) [35, 36], was also considered in order to investigate the effectiveness of a compatible product with the PUR mask. Van Oosten [14] reported that a similar product with another aliphatic PUR ester dispersion (Impranil ${ }^{\circledR}$ DLV) was already tested to stabilize PUR foam material with promising results. Characteristics of the adhesives selected for investigation are presented in Table 1.

\section{Preparation of the adhesives and test strips}

Distilled aqueous solutions of $5 \%$ of Methocel A $15 \mathrm{LV}$, Tylose MH 300 and Tylose MH 1000 were prepared under continuous magnetic stirring at $20{ }^{\circ} \mathrm{C}$. $20 \%$ of wheat starch paste was heated for 30 min under constant stirring in distilled water. Extra $20 \mathrm{~mL}$ of distilled water were added to compensate for moisture lost during the cooking. Then, the wheat starch paste was sieved two times and consequently diluted with water to get a concentration of $10 \%$. The polyurethane dispersion PU 52 was used without any further preparation.

Before testing the adhesives on the original surfaces, the proper adhesion between the Japanese paper and the testing adhesives was assessed, as well as their resulting flexibility. For this a set of Japanese paper strips were embedded with the adhesive solutions (Table 1) and left to dry at $20{ }^{\circ} \mathrm{C}$ and $50 \% \mathrm{RH}$. Since the adhesives did not delaminate, the strips retained their original shape and demonstrated a good flexibility when pulled manually, they were all selected for further tests on the intended PUR elastomer and PP mannequin.

The PUR and PP surfaces were cleaned using a mildly damp fine-pored polyurethane sponge before being treated. The adhesives were applied in drops onto the paper strips and then gently pressed on the testing surface using a flat short-haired brush. Afterwards, the paper strips were left dry without further pressure at $20{ }^{\circ} \mathrm{C}$ and $50 \% \mathrm{RH}$ (Fig. 4). After 7 days, the gluing treatments were assessed visually and manually by pulling the strips to determine their adhesion to the substrates. In addition, the flexibility of the paper embedded with adhesives was determined after 7 days of drying by controlling the occurrence of cracks due to shrinkage and/or failure after a manual tension test.

\section{Results and discussion}

\section{Colorimetry}

The colorimetric analysis performed in May 2019 (after twenty-two months from the loan) highlighted two different colors of the humanoid mask. As reported in Fig. 5, two clusters were recognized for the pale pink and yellow regions (for sampling spots and coordinate values, see Additional file 1: Fig. S2 and Table S1), which showed $\Delta \mathrm{E}^{*}$ values of 1.6 and 2.5 respectively, after 5 months of monitoring. These variations indicate an ongoing color changing progress meanwhile the mask was stored in

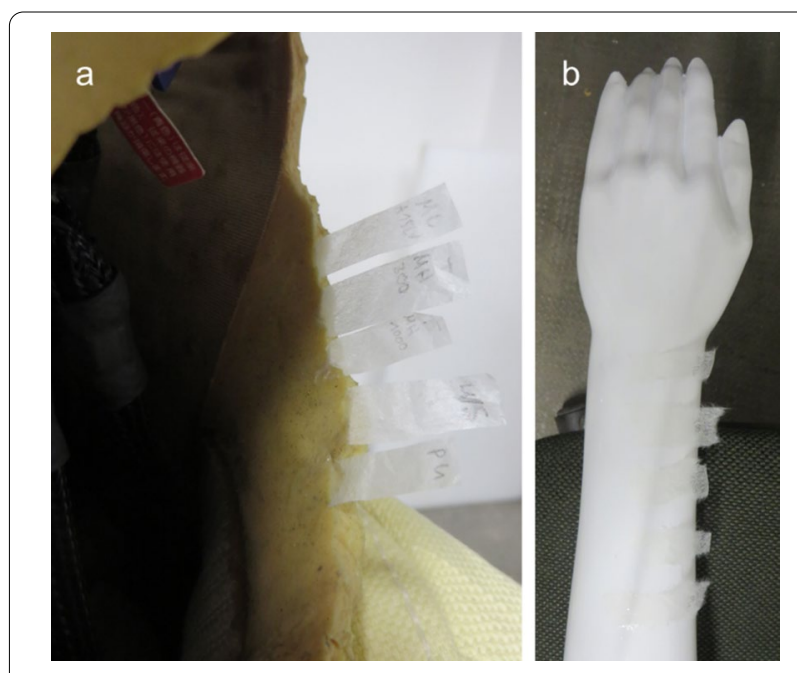

Fig. 4 Adhesion test on SAYA's neck (a) and PP mannequin (b) 


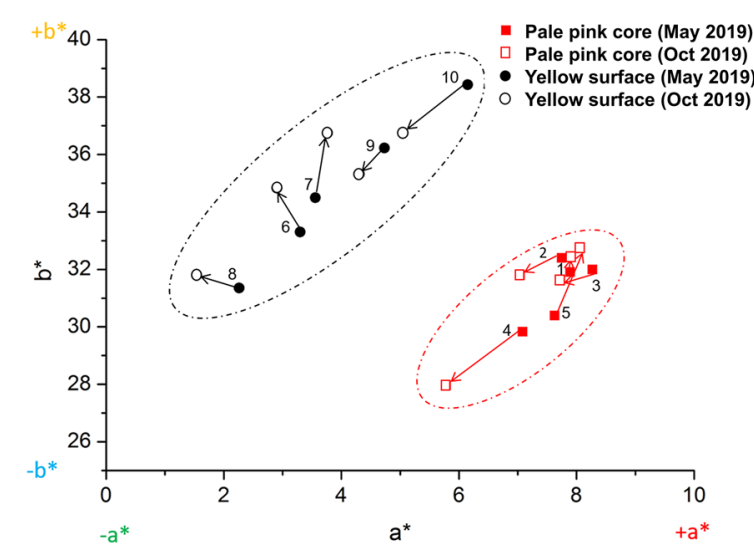

Fig. 5 Colorimetric values $\left(a^{*}, b^{*}\right)$ in two-dimensional CIELab Color Space of the pale pink areas (red 1-5 spots) and yellow areas (black 6-10 spots). The arrows show the change distance between May and October 2019. For the position of sampling spots, see Additional file 1: Fig. $\mathrm{S} 2$

laboratory conditions (ca. $22{ }^{\circ} \mathrm{C}, 40-60 \% \mathrm{RH}$, mostly kept in the dark and for short times exposed to $250 \mathrm{~lx}$ ). PUR elastomer, especially polyether- and aromatic isocyanates-based, is known to be very sensitive to light [19, 37-39]. In the SAYA mask case, the points uncovered by the cloths and wig yellowed with time. A clear color change trend was not observed for the other spots, highlighting the inherent complexity of the PUR elastomer degradation and its related discoloration over time.

\section{Microscopic and SEM-EDX investigations}

The appearance of the pale pink core differed from the yellow surface of the mask. In Fig. 6a, the pinkish part appears smooth, homogeneous and translucent, with only a few fibers attached on it. Instead, the yellowish surface (Fig. 6b) appears dirty with several soiling particles. The stickiness, a degradation phenomenon also observed in plastics like PVC, is likely caused by the migration of plasticizers to the surface, mainly in the liquid form such as bis(2-ethylhexyl)phthalate [39, 40].

The observation of the sample under SEM emphasized the two different morphologies between the consistent pale pink core $(\mathrm{P})$ and heterogeneous yellow surface $(\mathrm{Y})$ (Fig. 6c). The EDX analysis identified mainly carbon and oxygen for the pale pink area. Whereas the yellowed surface is characterized by further elements as magnesium $(\mathrm{Mg})$, aluminium ( $\mathrm{Al})$ and silicon $(\mathrm{Si})$, indicating the likely presence of aluminosilicates adhering to the sticky surface.

\section{Raman microscopy ( $\mu$-Raman)}

Only whitish particles were observed within the PUR elastomer under the coupled microscope, identified as Pigment White (PW) 6 (titanium dioxide, $\mathrm{TiO}_{2}$, C.I. n. 77891) as rutile and anatase crystalline form by $\mu$-Raman. As depicted in Fig. 7, overlapping signals from the two crystalline Raman signatures were detected. In the Raman spectrum, three bands of rutile $(R)$ at 226 (multi-photon process), $441\left(\mathrm{E}_{\mathrm{g}}\right)$ and $614\left(\mathrm{~A}_{1 \mathrm{~g}}\right) \mathrm{cm}^{-1}$ are observed, while only the most intense Raman-active optical phonon modes at $141\left(\mathrm{E}_{\mathrm{g}}\right) \mathrm{cm}^{-1}$ characterize the presence of anatase (A) [41-44]. Pigments based on $\mathrm{TiO}_{2}$ are the preferred white pigments used for polymers, including PUR [45]. The detection of both $\mathrm{TiO}_{2}$ crystalline forms reveals the use of this polymorphic mixture for the mask's pigmentation. The photochemistry of $\mathrm{TiO}_{2}$ has been subject of detailed research [46]. Studies have demonstrated how its presence could influence the photo-stability of several polymers [47-51]. In coloring plastics, the different photo-active properties of the two crystalline forms are well known [52]. Chen et al. [53] demonstrated the strong photo-sensitizing effect of anatase and, on the contrary, the photo-stabilizing properties of rutile against photo-oxidation of PUR under UV irradiation. The presence of the crystalline form anatase may impart a greater susceptibility of the elastomer to photo-oxidation.

No other pigments were identified in the PUR sample. A strong fluorescent background characterized the degraded polymeric matrix, limiting the $\mu$-Raman investigation and probably detecting the red component of the pink color. However, a possible composition of the pink pigment could be a mixture of $\mathrm{TiO}_{2}$ with iron oxides, Pigment Red (PR) 101 and Pigment Yellow (PY) 42 (and traces of Pigment Black (PBk) 7, carbon black), as reported in the safety data sheet of the pink pigment produced by the Japanese manufacturer of the PUR elastomer [54]. These pigments are known in the literature for the coloring of PUR [45]. The inorganic pigments used for the pink coloring could have been dispersed in small quantities and are known for having a small size (10$30 \mu \mathrm{m}$ ) [45], which made their identification in polymeric matrix a challenge. No differences between the pale pink core and the yellow surface were observed.

\section{ATR-FTIR}

Figure 8 shows the spectra of the pale pink core and the yellow surface of the mask. The band assignments are reported in Table 2. Similar absorption bands characterize the two samples, with the characteristic stretching vibration $\mathrm{C}-\mathrm{O}-\mathrm{C}$ at $1100 \mathrm{~cm}^{-1}$ of the polyether-based PUR [18, 39, 55]. Other typical features are: (1) the bands at $2966 \mathrm{~cm}^{-1}, 2928 \mathrm{~cm}^{-1}$ and $2870 \mathrm{~cm}^{-1}$ of $\mathrm{CH}_{3}$ and $\mathrm{CH}_{2}$ stretching; (2) $1727 \mathrm{~cm}^{-1}$ band of the urethane $\mathrm{C}=\mathrm{O}$ group; (3) $1530 \mathrm{~cm}^{-1}$ band of the $\mathrm{N}-\mathrm{H}$ bend vibration with $\mathrm{C}-\mathrm{N}$ stretch vibration in the $-\mathrm{C}-\mathrm{NH}$ group (amide 


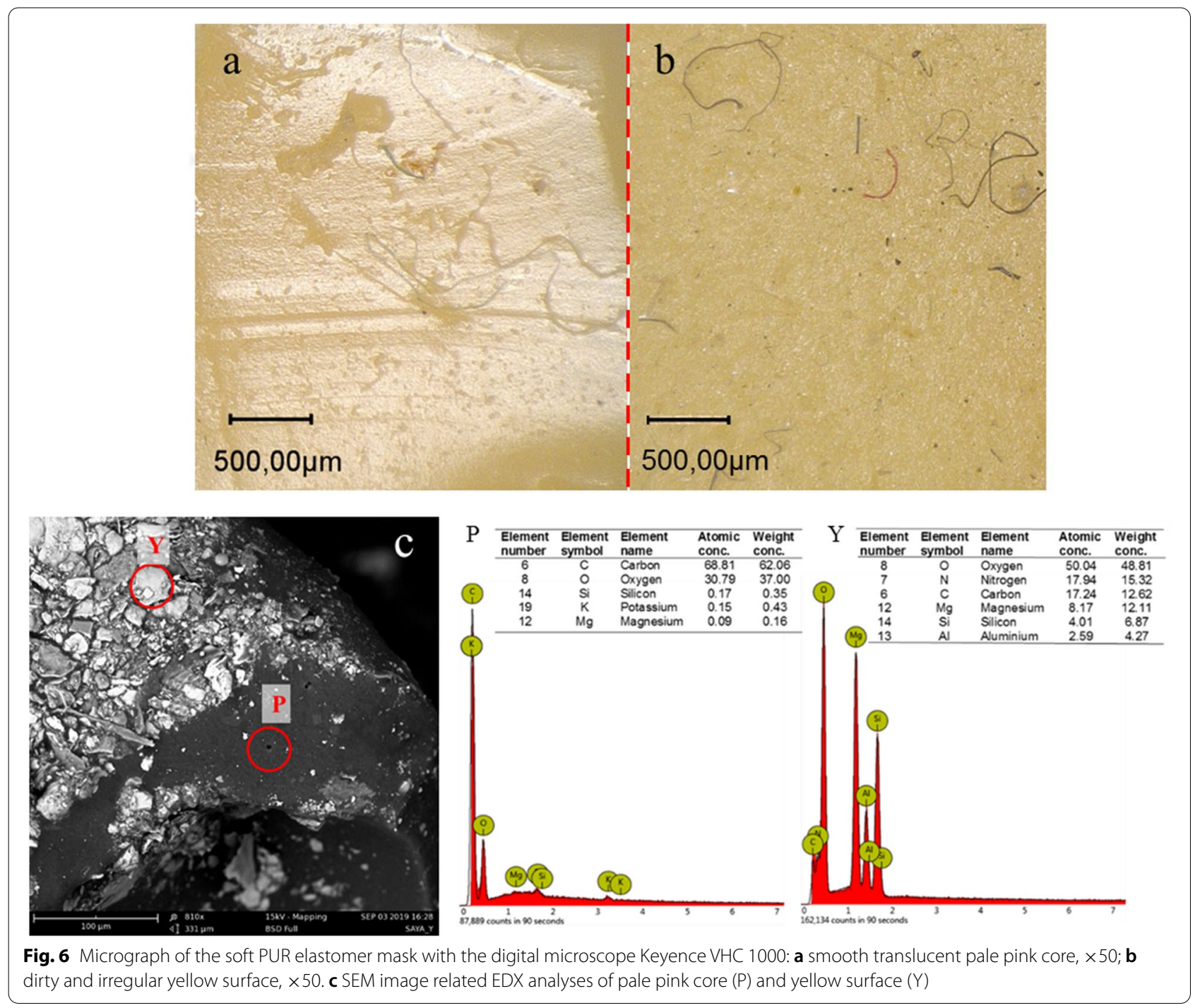

II band); 4) $1273 \mathrm{~cm}^{-1}$ band of the $\mathrm{C}-\mathrm{O}$ stretch $[19,38$, 52-58]. However, the typical band between 3340 and $3320 \mathrm{~cm}^{-1}$ of the stretching vibration of $\mathrm{N}-\mathrm{H}$ group is weak. This could indicate the loss of the urethane structures due to UV exposure $[19,59]$ or the low amount of urethane bonds in the plastic formulation [11].

Besides the characteristic IR bands of the PUR elastomer, slight differences were recognized between the pale pink core and yellowed surface, as highlighted by the negative and positive intensities in the spectrum (Fig. 8). Especially for the yellowed surface, the band at $3674 \mathrm{~cm}^{-1}$ of hydroxyl stretching band and the peaks at $1039 \mathrm{~cm}^{-1}$ and $1015 \mathrm{~cm}^{-1}$ ascribed to in-plane $\mathrm{Si}-\mathrm{O}$ vibrations, could indicate the presence of aluminum silicates (e.g. kaolinite) on the surface as attached dust particle [23], which confirms the EDX analysis (dust presence).
Moreover, when compared with the bands of the pale pink core, the spectrum of yellowed sample denotes a slight decrease of intensity of the following bands: (1) $\mathrm{C}-\mathrm{H}$ stretch vibrations in the $3000-2800 \mathrm{~cm}^{-1}$ region attributed to the vibrations of the methylene groups; (2) the urethane $\mathrm{C}=\mathrm{O}$ stretch free at $1727 \mathrm{~cm}^{-1}$; (3) the band at $1100 \mathrm{~cm}^{-1}$ of the $\mathrm{C}-\mathrm{O}-\mathrm{C}$ stretching vibrations of the ether group (Additional file 1: Fig. S3) [19, 37]. These changes can be correlated with the beginning of the production of quinone structures, which led to yellowing [19]. It is known that the aromatic structures of PUR are oxidized by UV radiation in the central methylene group, resulting in conjugated quinones and, therefore in the formation of colored products and loss of physical and mechanical properties [10, 19, 37]. 


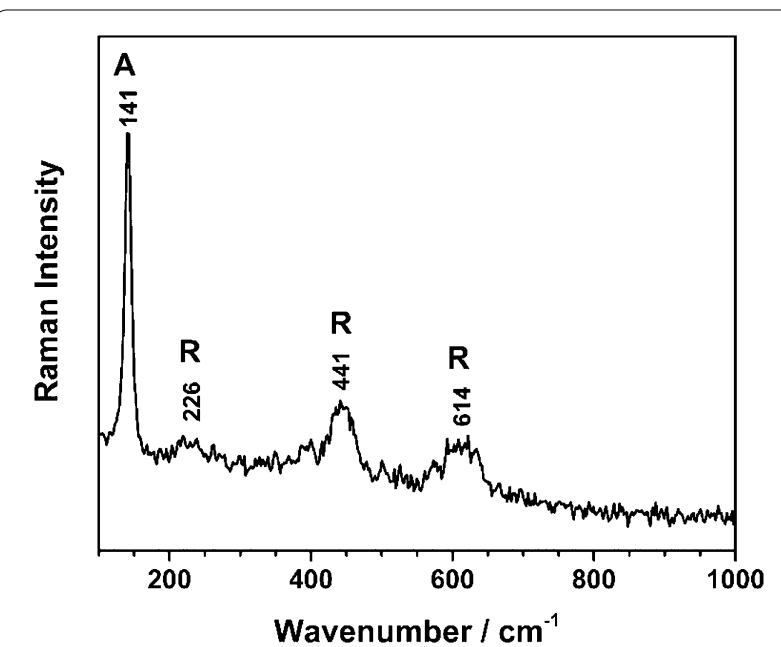

Fig. 7 Raman spectrum of PW 6 in anatase (A) and rutile (R) crystalline forms identified in the PUR elastomer mask. The spectrum is presented as acquired without baseline correction or other treatment

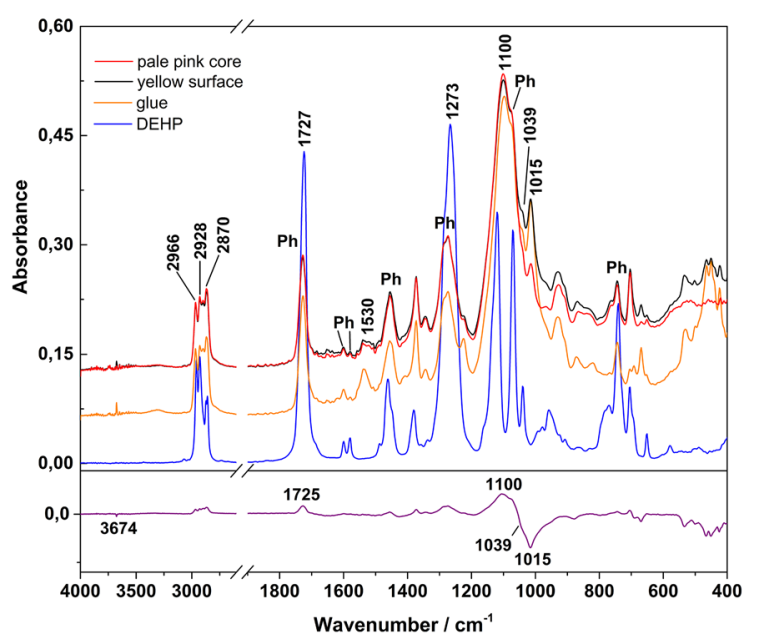

Fig. 8 ATR-FTIR spectra of the SAYA mask: pale pink core (red line), yellow surface (black line), glue (orange line), reference spectrum of bis(2-ethylhexyl)phthalate (DEHP) (blue line), difference between the spectrum of the pale pink core and yellow surface (violet line). The spectra are presented as acquired without baseline correction

Both spectra (pale pink core and yellowed surface) present characteristic absorption bands of phthalate. As shown for the reference spectrum of di(2-ethylhexyl) phthalate (DEHP) (Fig. 8, blue line), the main absorptions are: $1727 \mathrm{~cm}^{-1}(v \mathrm{C}=\mathrm{O}$ of $\mathrm{O}=\mathrm{C}-\mathrm{O}), 1600 \mathrm{~cm}^{-1}$ and $1580 \mathrm{~cm}^{-1}$ ( $v \mathrm{C}=\mathrm{C}$ of benzene ring), $1464 \mathrm{~cm}^{-1}(v$ $\mathrm{C}-\mathrm{H}), 1273 \mathrm{~cm}^{-1}(v \mathrm{C}-\mathrm{O}$ of $\mathrm{O}=\mathrm{C}-\mathrm{O})$, the shoulder at $1077 \mathrm{~cm}^{-1}\left(v \mathrm{C}-\mathrm{O}\right.$ of $\left.\mathrm{O}-\mathrm{CH}_{2}\right)$ and $744 \mathrm{~cm}^{-1}(v \mathrm{C}-\mathrm{H})[15$, $39,60,61]$. The band at $744 \mathrm{~cm}^{-1}$, used to discriminate the presence of phthalate from the polymeric matrix, resulted slightly increased in the yellowed surface compared to the pale pink core, a signal of the plasticizer migration to the surface (Additional file 1: Fig. S4). No FTIR signals correlated with the presence of pigments were observed in PUR samples, probably because of the low pigment concentration, well below the detection limit of the technique (around $<3 \%$ ) [62].

The spectrum of the glue found on the reverse side of the mask is also shown in Fig. 8. The absorbance bands are comparable to those reported for the mask samples, which determine its composition as a PUR ether-based adhesive. Further bands are at $3294 \mathrm{~cm}^{-1}$ (stretching vibration of $\mathrm{N}-\mathrm{H}$ ), $1534 \mathrm{~cm}^{-1}$ (amide II band) and at $1224 \mathrm{~cm}^{-1}$ (amide III) [19, 37, 63]. Moreover, the main absorption bands for phthalate were also identified at the glue's surface. The Japanese team probably decided to use a PUR glue chemically compatible with the PUR elastomer. PUR adhesives are extensively used in several applications for their good adhesion on many substrates, good toughness, excellent flexibility, durability, resistance to water, and a broad range of chemicals [64-66]. PUR is known to form hydrogen bonds and covalent bonds when active hydrogen is present [20]. As described in the previous section (see The SAYA mask), the areas with an internal layer of glue have a pale pink color similar to the original one. This fact could suggest the positive effect of the glue to act as a barrier against oxygen, slowing down the yellowing process that characterizes the other areas of the mask. Further research is needed to investigate this aspect.

The spectrum of the sample from the skull revealed to be made of glass fiber reinforced polyester, as presented and discussed in Additional file 1: Fig. S5 and Table S2.

\section{EGA-MS}

Figure 9 (top) shows the EGA-MS thermograms of the pale pink core and the yellow surface. For both samples, two thermal decomposition zones are identified: zone 1 from 160 to $330{ }^{\circ} \mathrm{C}$ and zone 2 from 330 to $500{ }^{\circ} \mathrm{C}$. The first band describes the evolved gas emitted by additives, with the most abundant ions in the mass spectrum of $\mathrm{m} / z$ 43, 57, 71, 85, 127, 149167,279 and 293 (Fig. 9a, c). These ions suggested the presence of phthalates used as plasticizers, in particular diisononyl phthalate (DINP, quantitative ion $\mathrm{m} / z$ 293, confirmation ions $m / z 149,267$ ) and DEHP (quantitative ion $m / z 279$, confirmation ions $m / z 149,167)[67,68] .{ }^{2}$ The second band is related to the pyrolysis of the PUR,

\footnotetext{
${ }^{2}$ The presence of DINP and DEHP in the PUR elastomer were confirmed by TD-GC/MS analysis (see the paragraph Double-shot - GC/MS).
} 
Table 2 Vibrational band assignments for the ATR-FTIR spectra of the pale pink core and yellow surface of the SAYA mask

\begin{tabular}{|c|c|c|}
\hline Wavenumber $\left(\mathrm{cm}^{-1}\right)$ & Assignment & References \\
\hline 3674 & $\vee \mathrm{O}-\mathrm{H}$ free & {$[23]$} \\
\hline $3350-3250$ & $\vee N H$ & {$[13,19,39,59]$} \\
\hline 2966 & va $\mathrm{C}-\mathrm{H}_{3}$ & {$[13,15,17-19,38,60]$} \\
\hline 2928 & va C- $\mathrm{H}_{2}$ & {$[13,15,17-19,38,60]$} \\
\hline 2870 & vs $\mathrm{C}-\mathrm{H}_{3}$ & {$[13,15,17-19,38,60]$} \\
\hline 1727 & $\vee C=O$ & {$[13,38,56,61]$} \\
\hline 1649 & $\vee C=C$ in alkanes & {$[21,62]$} \\
\hline 1600 & $\vee C=C$ (benzene ring) & {$[13,15,17-19,39,56,60,61]$} \\
\hline 1580 & $\vee C=C$ (benzene ring) & {$[13,17,18,39,56,60,61]$} \\
\hline 1530 & $\delta \mathrm{O}=\mathrm{C}-\mathrm{N}-\mathrm{H} ; \vee \mathrm{O}=\mathrm{C}-\mathrm{N}-\mathrm{H}$ & {$[17-19,39]$} \\
\hline 1454 & $\delta a \mathrm{C}-\mathrm{H}_{3}$ & {$[13,17,18,38]$} \\
\hline 1373 & $\delta s \mathrm{C}-\mathrm{H}_{3}$ & {$[13,17,18,38]$} \\
\hline 1345 & $\omega \mathrm{C}-\mathrm{H}_{2}$ & {$[13,17,18]$} \\
\hline 1273 & $\vee C-O$ & {$[60,61]$} \\
\hline 1100 & va C-O-C Polyether-based polyol & {$[15,18,38,39,55]$} \\
\hline 1077 shoulder & $\vee C-O$ & {$[38,39,60,61]$} \\
\hline 1039 & $\mathrm{Si}-\mathrm{O}$ & {$[23]$} \\
\hline 1015 & $\mathrm{Si}-\mathrm{O}$ & {$[23]$} \\
\hline 933 & $\rho C-\mathrm{H}_{3}$ & {$[17,18,38]$} \\
\hline 744 & $\vee C-H$ & {$[38,39,60,61]$} \\
\hline 669 & Amide $V$ urethane seg & {$[37]$} \\
\hline
\end{tabular}

characterized by the ions $m / z 43,59,73,91,104$ and 117 (Fig. 9b, d). La Nasa et al. [17] and Neumann et al. [69] reported that these fragments are attributable to the soft segments of polyether polyols of PUR. The presence of the hard segment of PUR, whose volatilization presumably occurred between 250 and $300{ }^{\circ} \mathrm{C}$ [70], was not identified probably due to the too intense signal of the additives.

Focusing on the mass spectra, the thermal zones of the two samples are similar (Fig. 9a-d). However, their EGA profiles present differences. While the temperature of the second step of the polymer did not change with a peak centered at $404{ }^{\circ} \mathrm{C}$, the temperature of first step related to the evolution of additives slightly shifted from $268{ }^{\circ} \mathrm{C}$ for the pale pink core to $273{ }^{\circ} \mathrm{C}$ for the yellowed surface. This shift could be due to the two main phthalates present in different ratios in the bulk and at the surface (i.e. their different speed of migration towards the surface or their different evaporation rates). Moreover, the ratio between the intensities of the bands changed: the pale pink inner core sample is characterized by a less intense band of additives than that of the polymer; the yellowed surface sample, instead, presents a more intense additive band and a reduction of the band related to the polymer. These variations could be due to the mask aging, especially regarding the migration of the plasticizer and, its consequent enrichment to the surface of the mask, causing the stickiness phenomenon [71]. Plasticizers in the formulation were necessary to create soft and elastic PUR elastomer material to reproduce the human skin.

\section{Double-shot-GC/MS}

Figure 10 shows the volatile organic compounds detected with the first step of the analysis (TD-GC/MS) of the pale pink core and the yellow surface. The peak identification is reported in Table 3. The presence of the phthalates DEHP ( $\left.n^{\circ} 19\right)$ and DINP $\left(n^{\circ} 21\right)$ as plasticizers was confirmed and traces of diethyl phthalate (DEP, $\left.n^{\circ} 12\right)$ and dibutyl phthalate (DBP, $\left.n^{\circ} 16\right)$ were also identified. Moreover, the UV stabilizer 2-( $2^{\prime}$-hydroxy, $3^{\prime}, 5^{\prime} \mathrm{di}$ tert-amylphenyl) benzotriazole (Tinuvin $328, n^{\circ} 20$ ) was detected, as well as the principal components of the polymer, e.g. propylenglycol $\left(\mathrm{n}^{\circ} 3\right)$, diisopropyl ether $\left(\mathrm{n}^{\circ} 4\right)$ and methylene diphenyl diisocyanate (MDI) ( $\left.\mathrm{n}^{\circ} 17\right)$. The identification of MDI supports the finding of FT-IR analysis and corroborates the photo-oxidation of the PUR mask and, therefore, its visible yellowing [19]. Besides PUR, specific fragments of another polymer were recognized: small peaks, which became more intense in the pyrograms, related to styrene-acrylonitrile $\left(\mathrm{SAN}, \mathrm{n}^{\circ} 6,10\right.$, 

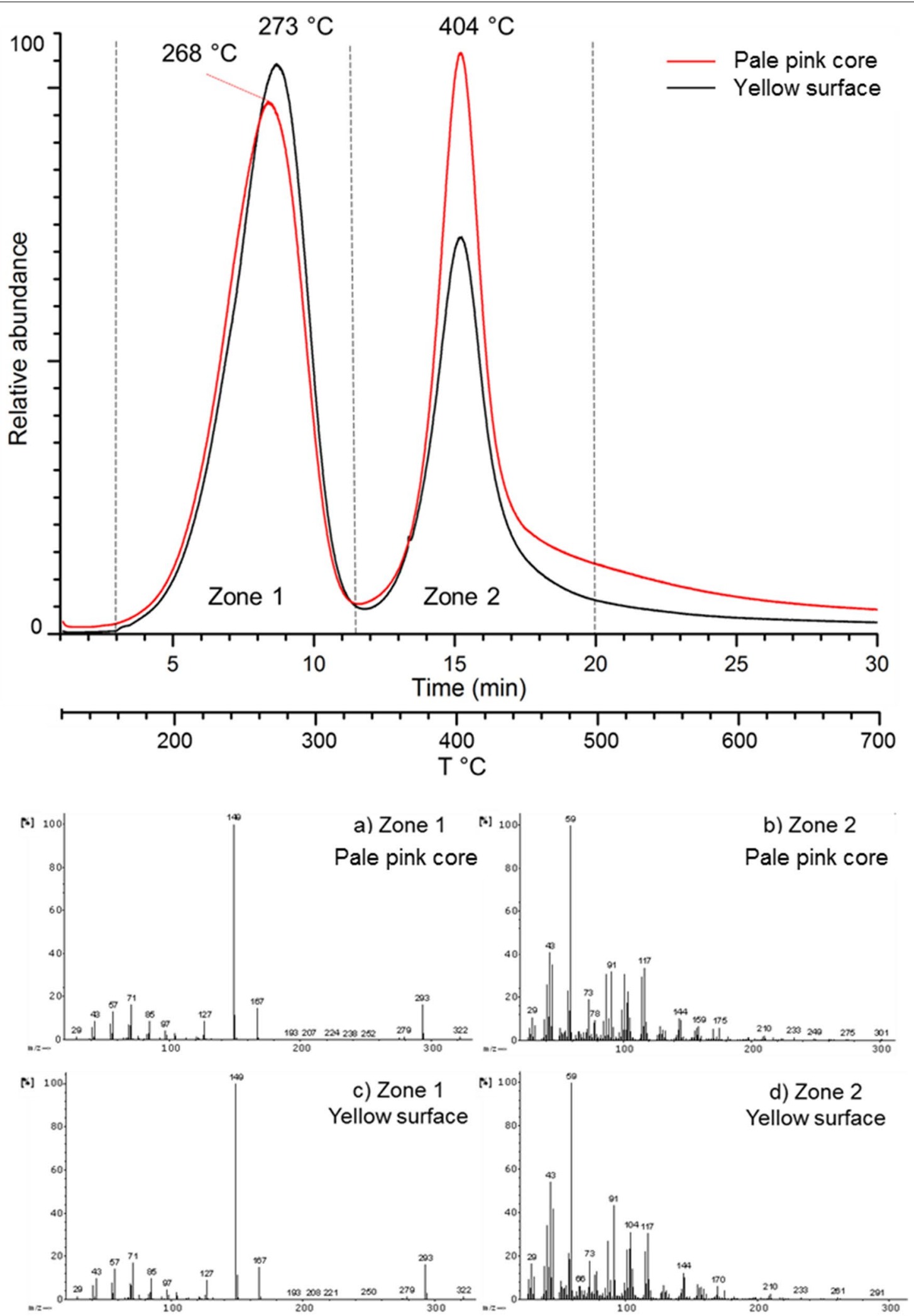

Fig. 9 EGA-thermograms of the pale pink core (red line) and the yellow surface (black line) of PUR mask. The mass spectra obtained for zone 1 $\left(160-330^{\circ} \mathrm{C}\right)$ and zone $2\left(330-500^{\circ} \mathrm{C}\right)$ are also reported 


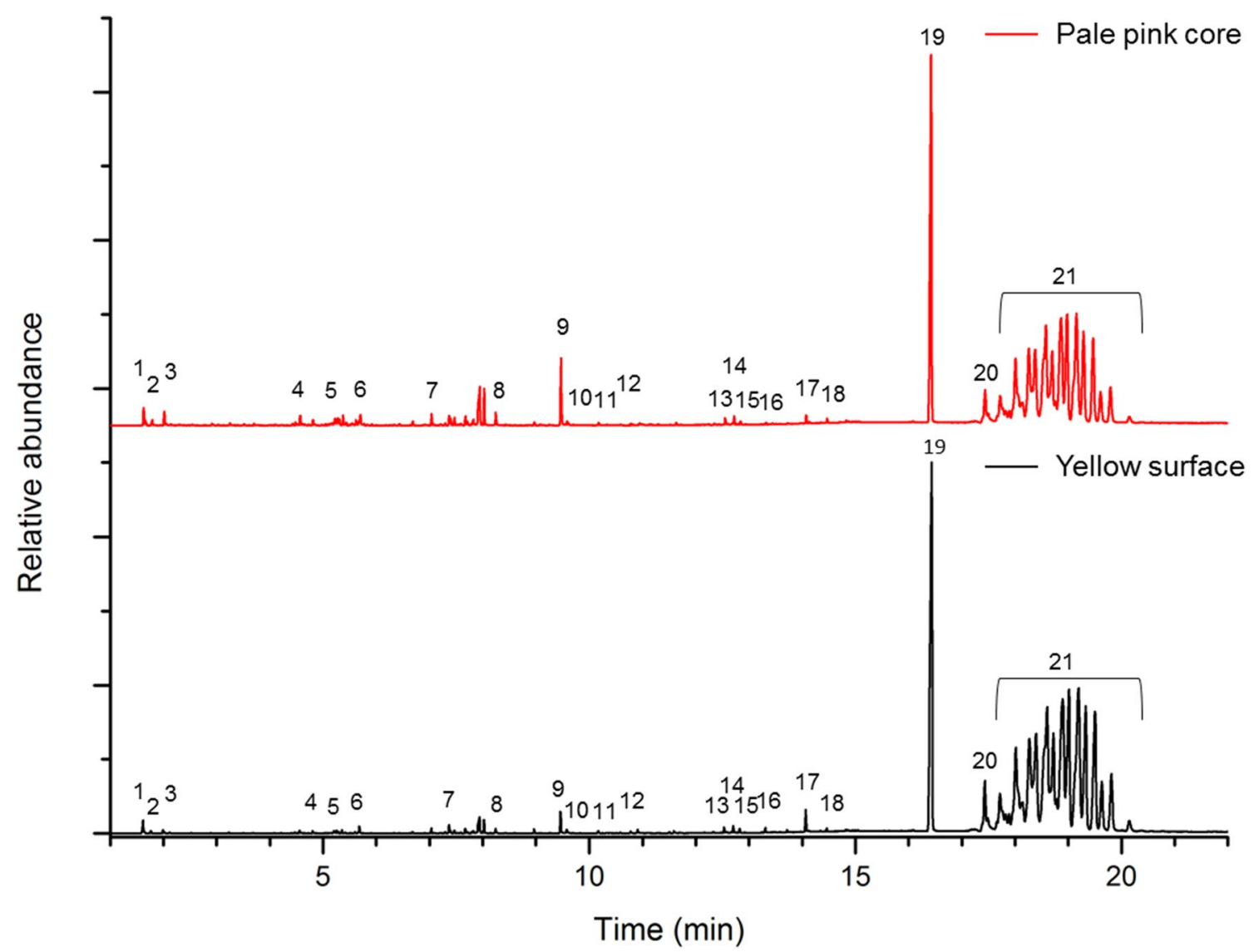

Fig. 10 Normalized TD-chromatograms of the pale pink core (in red) and the yellow surface (in black) of PUR mask. Peak identification is reported in Table 3

$11,13-15,18)$ were identified. The presence of SAN is discussed later in the text.

Considering the results of the pale pink core and the yellowed surface, a relative increase of the abundance of the main additives DEHP ( $\left.\mathrm{n}^{\circ} 19\right)$, Tinuvin $328\left(\mathrm{n}^{\circ} 20\right)$ and DINP ( $\left.\mathrm{n}^{\circ} 21\right)$ was detected on the yellow surface (see Additional file 1: Table S3). These results confirm those obtained from the EGA-MS analysis regarding the additive migrations to the mask's surface. This degradation process is already well known for plastics with a high amount of additives, such as PVC [39, 72, 73].

Figure 11 shows the pyrograms of the mask obtained in the second step (Py-GC/MS analysis) at $600{ }^{\circ} \mathrm{C}$. The relative peaks are reported in the Table 3. Diisopropyl ether ( $\mathrm{n}^{\circ}$ 26) and 2-propanone, 1-(1-methylethoxy)-( $\mathrm{n}^{\circ}$ 27) were the main compounds from the PUR polymer. All the other fragments, instead, belonged to the pyrolysis of the SAN amount, in particular: acrylonitrile $\left(\mathrm{n}^{\circ}\right.$ $23)$, styrene ( $\left.n^{\circ} 29\right), \alpha$-methylstyrene ( $\left.n^{\circ} 31\right)$, 4-phenylbutyronitrile ( $\left.\mathrm{n}^{\circ} 33\right)$, SA: 4-phenylpent-4-enenitrile $\left(\mathrm{n}^{\circ} 34\right)$, 2-methylene-4-phenethylpentadinitrile ( $\left.\mathrm{n}^{\circ} 35\right)$, 2-methylene-4-phenylheptanedinitrile ( $\left.n^{\circ} 36\right), 2-(2-$ phenylallyl) pentanedinitrile ( $\left.\mathrm{n}^{\circ} 37\right)$ and 2-phenethyl-4-phenylpent4-enenitrile $\left(\mathrm{n}^{\circ} 38\right)$ [27]. The presence of SAN in PUR museum objects was already observed by Izzo et al. [29], as an additive capable of improving the mechanical properties of PUR polymers [74]. Its presence, however, could have also influenced the photo-stability of the PUR elastomer negatively. SAN is known to turn yellow in color when exposed to light and oxygen due to photo-oxidative degradation of the polystyrene component $[75,76]$.

When comparing the two sample's compositions, no significant differences were detected. This could mean that the degradation process of PUR mask is still at an initial stage and has not yet caused evident chemical alterations in the polymeric matrix composition.

\section{Assessment of the adhesive treatment effectiveness}

The results of the adhesion tests are summarized in Table 4 . The cellulose-based adhesives gave good results 
Table 3 Major peak identification in the TD-step (from 50 to $320^{\circ} \mathrm{C}$ ) and in the Py-step $\left(600{ }^{\circ} \mathrm{C}\right.$ ) of the pale pink core and yellow surface of PUR elastomer

\begin{tabular}{|c|c|c|}
\hline Peak number & Peak identification & Main ions $(m / z)$ \\
\hline & TD-step & \\
\hline 1 & Acetaldehyde & $40,41,42,43, \underline{44}$ \\
\hline 2 & Propylene oxide & $29,43, \underline{\mathbf{5 8}}$ \\
\hline 3 & Propylenglycol & $43, \underline{45}, 76$ \\
\hline 4 & Diisopropyl ether & $44, \underline{45}, 87,102$ \\
\hline 5 & 2-Ethyl-1-hexene & $41,42,55, \underline{70}, 112$ \\
\hline 6 & Styrene & $51,77,78, \underline{104}$ \\
\hline 7 & 2-Ethylhexanol & $41,55, \underline{57}, 70,83,98,130$ \\
\hline 8 & 1-Nonanol & $29,41, \underline{56}, 70,83,97,126$ \\
\hline 9 & Phthalic anhydride & $50,76, \underline{104}, 148$ \\
\hline 10 & 4-Phenylbutyronitrile & $51,65,77, \underline{91}, 104,115,145$ \\
\hline 11 & 4-Phenylpent-4-enenitrile (hybrid dimer) & $51,63,77,91,103, \underline{115}, 117,130,142,157$ \\
\hline 12 & Diethyl phthalate (DEP) & $50,65,76,105,149,177,222$ \\
\hline 13 & 2-Methylene-4-phenyl heptanedinitrile (hybrid trimer) & $51,65,77, \underline{91}, 105,156,209,210$ \\
\hline 14 & 2-Methylene-4-phenethyl pentanedinitrile (hybrid trimer) & $51,65,77,91,104,117,128, \underline{144}, 210$ \\
\hline 15 & 2-(2-Phenylallyl)pentadinitrile (hybrid trimer) & $51,65,77,91,104,118,129,144,156,170,198,210$ \\
\hline 16 & Dibutyl phthalate (DBP) & $76,104,149,204,278$ \\
\hline 17 & Methylene diphenyl diisocyanate (MDI) & $77,132,165,180,208,221, \underline{\mathbf{2 5 0}}$ \\
\hline 18 & 2-Phenethyl-4-phenylpent-4-enenitrile (hybrid trimer) & $51,65,77, \underline{91}, 105,115,118,129,142,156,170,261$ \\
\hline 19 & Bis(2-ethylhexyl)phthalate (DEHP) & $43,57,71,104, \underline{149}, 167,279,390$ \\
\hline 20 & 2-(2'-Hydroxy, 3',5'-di-tert-amylphenyl)benzotriazole (Tinuvin 328) & $43,71,92,149,252, \underline{322}, 351$ \\
\hline \multirow[t]{2}{*}{21} & Diisononyl phthalate (DINP) & $43,57,71,85,97,127, \underline{149}, 167,293,418$ \\
\hline & Py-step & \\
\hline 22 & Propylene & $38,39,40,41,42$ \\
\hline 23 & Acrylonitrile & $50,51,52, \underline{\mathbf{5 3}}$ \\
\hline 24 & Metacrylonitrile & $39, \underline{41}, 52,67$ \\
\hline 25 & Pentenenitrile & $39,41, \underline{54}, 66,81$ \\
\hline 26 & Diisopropyl ether & $41,43, \underline{45}, 59,87,102$ \\
\hline 27 & 2-Propanone, 1-(1-methylethoxy)- & $41, \underline{43}, 58,73,116$ \\
\hline 28 & Ethylbenzene & $51,65,77, \underline{91}, 106$ \\
\hline 29 & Styrene & $51,63,78, \underline{104}$ \\
\hline 30 & Isopropylbenzene & $51,77,91, \underline{105}, 120$ \\
\hline 31 & a-Methylstyrene & $51,63,78,91,103, \underline{118}$ \\
\hline 32 & 2-Methylenepentanedinitrile & $52, \underline{66}, 79,106$ \\
\hline 33 & 4-Phenylbutyronitrile & $51,65,77, \underline{91}, 104,115,145$ \\
\hline 34 & 4-Phenylpent-4-enenitrile (hybrid dimer) & $51,63,77,91,103, \underline{115}, 130,142,157$ \\
\hline 35 & 2-Methylene-4-phenethyl pentanedinitrile (hybrid trimer) & $51,65,77, \underline{91}, 105,156,209,210$ \\
\hline 36 & 2-Methylene-4-phenyl heptanedinitrile (hybrid trimer) & $51,65,77,91,104,117, \underline{144}, 210$ \\
\hline 37 & 2-(2-Phenylallyl)pentadinitrile (hybrid trimer) & $51,57,65,77,91,104, \underline{118}, 129,144,156,170,198,210$ \\
\hline 38 & 2-Phenethyl-4-phenylpent-4-enenitrile (hybrid trimer) & $51,65,77, \underline{91}, 105,115,118,129,142,156,170,261$ \\
\hline
\end{tabular}

Characteristic ions in mass spectra: molecular weight $\left(M_{w}\right)$ bold, base peak underlined

on SAYA PUR elastomer, with the exception of Methocel A $15 \mathrm{VL}$, while not good adhesion was found for the PP mannequin. The best results were obtained with the wheat starch paste and PU 52 in both supports. The PUR dispersion was the unique adhesive with good flexibility. Because of its good adhesion properties and chemical compatibility with the mask's composition, a complete treatment of the tears was suggested to the museum staff as adequate. 


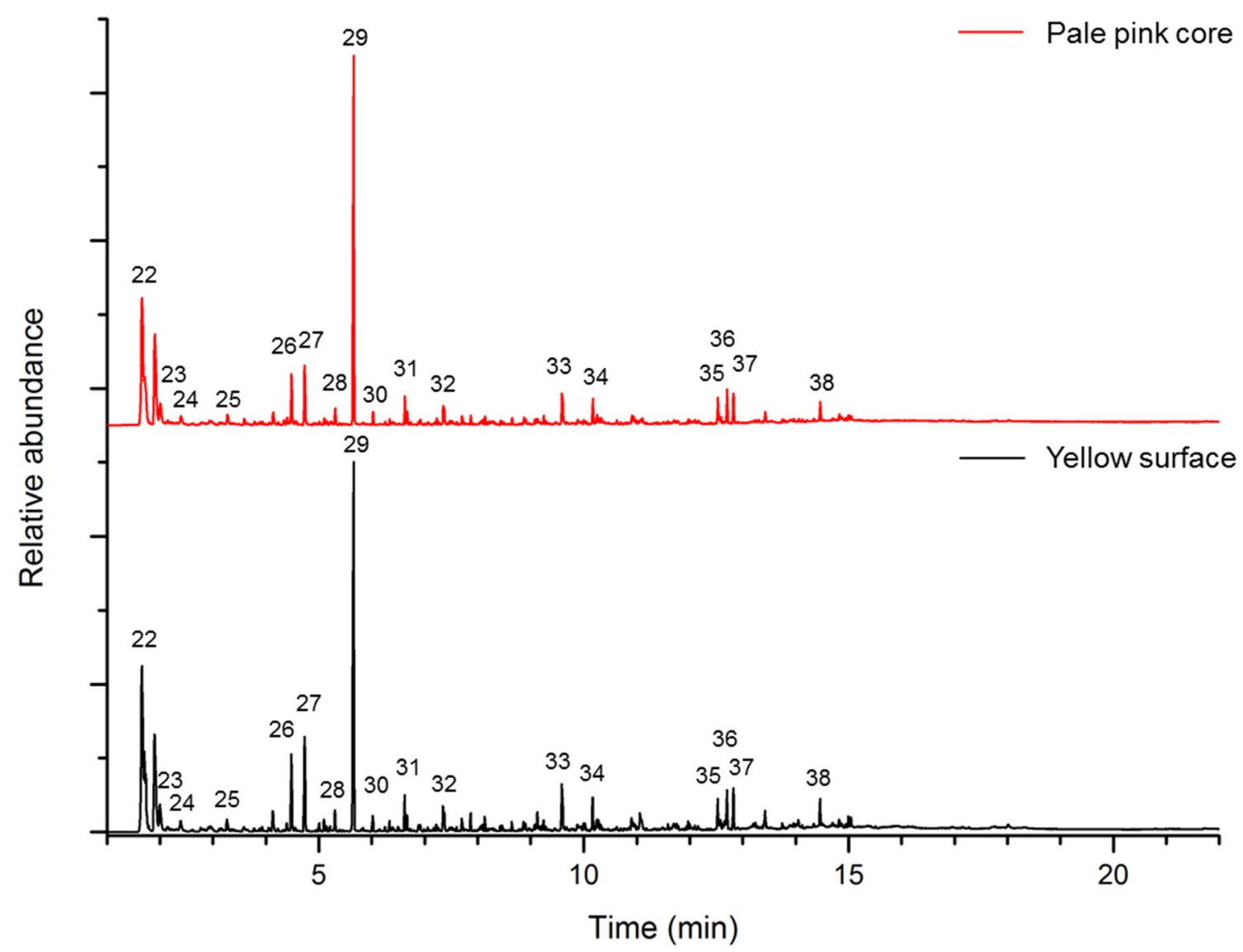

Fig. 11 Normalized Py-GC/MS chromatograms of the pale pink core (in red) and the yellow surface (in black) of SAYA mask. Peak identification is reported in Table 3

Table 4 Results of the adhesion and flexibility tests

\begin{tabular}{llll}
\hline Adhesive & $\begin{array}{l}\text { Adhesion on } \\
\text { PUR }\end{array}$ & $\begin{array}{l}\text { Adhesion } \\
\text { on PP }\end{array}$ & Flexibility \\
\hline Methocel A 15 LV (5\%) & 0 & - & - \\
Tylose MH 300 (5\%) & + & 0 & 0 \\
Tylose MH 1000 (5\%) & + & 0 & - \\
Wheat starch paste (10\%) & + & + & 0 \\
PUR dispersion PU 52 & + & + & + \\
\hline
\end{tabular}

+: good; 0: mediocre; -: poor

\section{Conclusions}

The multi-analytical approach applied in this study allowed a comprehensive characterization of the material composition of SAYA's facial/skin mask and its degradation. This study confirms how the joint application of in situ ATR-FTIR and $\mu$-Raman, with $\mu$-destructive EGA-MS and TD/Py-GC/MS analyses is a successful approach for addressing unknown complex plastic formulation at any level of degradation to be applied also in future studies.

This paper highlights the inherent complexity and chemical instability of PUR elastomer-based artifacts, and the color change detected within 5 months of monitoring pointed out a still ongoing degradation. After only 10 years from the production, this alteration extent is likely a result of the chemical composition of the mask, which makes it deeply susceptible to changes.

Based on the results of this study and literature discussion, two main degradation processes might be assumed: (a) photo-oxidation of the MDI-PUR elastomer, responsible for the yellowing and loss of physical and mechanical properties, enhanced by the presence of anatase form and SAN in the formulation; (b) migration of UV stabilizer and phthalates to the surface, which, especially for phthalates (DINP and DEHP), caused a widespread stickiness and the consequent attachment of dust particles. The role of UV-stabilizer in the color change needs still clarification as literature suggests decay leading to possible yellowing $[77,78]$. 
The specific knowledge of SAYA's mask composition and degradation supported interdisciplinary discussions with the team of curators and conservators of the Deutsches Museum. Even though a possible adhesion treatment could be suggested to minimize further degradation, additional research is necessary, including the long-term stability of the treatment through accelerated aging experiments.

\begin{abstract}
Abbreviations
BSD: Backscatter electron detector; CIE: Commission internationale de l'éclairage; DBP: Dibutyl phthalate; DEHP: Bis(2-ethylhexyl)phthalate; DEP: Diethyl phthalate; DINP: Diisononyl phthalate; EGA-MS: Evolved gas analysismass spectrometry; FRP: Fiber reinforced plastic; FTIR-ATR: Fourier transform infrared spectroscopy in attenuated total reflection; MDI: Methylene diphenyl diisocyanate; $\mathrm{M}_{\mathrm{w}}$ : Molecular weight; PP: Polypropylene; PUR: Polyurethane; PVC: Polyvinylchloride; SAN: Styrene acrylonitrile; SEM-EDX: Scanning electron microscope-energy dispersive X-ray spectroscopy; TD/Py-GC/MS: Thermal desorption/pyrolysis-gas chromatography/mass spectrometry; UV: Ultraviolet.
\end{abstract}

\section{Supplementary Information}

The online version contains supplementary material available at https://doi. org/10.1186/s40494-021-00636-8.

Additional file 1. Plastics in robots: a degradation study of a humanoid skin mask made of soft urethane elastomer.

\section{Acknowledgements}

The authors would like to thank Dr. Clarimma Sessa, of the Chair of Conservation-Restoration, Art Technology and Conservation Science at the TUM for her support with SEM-EDX investigations; Prof. Takuya Hashimoto of the Tokyo University of Science for sharing information about the robot SAYA; Dr. Frank Dittmann, Nicolas Lange and Susanne Grießbach, curators and conservator of the Deutsches Museum respectively, for the fruitful discussions on the decision-making-process regarding the preservation of SAYA.

\section{Authors' contributions}

MP and AM defined the research project and designed the experiments. AM, MP and EMS performed the analyses, the data analysis and interpretation. JS performed the conservation treatment and gave recommendations for preventive conservation and storage. AM wrote the first draft manuscript and all co-authors discussed the results and commented on the manuscript. All authors reviewed, edited the final manuscript. All authors read and approved the final manuscript.

\section{Funding}

Open Access funding enabled and organized by Projekt DEAL. This research was not supported or funded by any specific grant. The Deutsches Museum financed the Scholar in Residence scholarship of Julia Sawitzki and provided the equipment, the infrastructure and the human resources.

\section{Availability of data and materials}

All data generated or analyzed during this study are included in this published article [and its supplementary information files].

\section{Declarations}

\section{Competing interests}

The authors declare that they have no competing interests.

\section{Author details}

${ }^{1}$ Conservation Science Department, Deutsches Museum, Museumsinsel 1, 80538 Munich, Germany. ${ }^{2}$ Department of Conservation and Restoration and LAQV-REQUIMTE, Nova School of Science and Technology, 2829-516 Monte da Caparica, Portugal.

Received: 11 October 2021 Accepted: 10 December 2021

Published online: 05 January 2022

\section{References}

1. Breazeal C. Emotion and sociable humanoid robots. Int J Hum-Comput St. 2003:59(1-2):119-55. https://doi.org/10.1016/S1071-5819(03)00018-1.

2. Hashimoto T, Hiramatsu S, Kobayashi H. Development of face robot for emotional communication between human and robot. In: Robotics Society of Japan, editor. Proceedings, 2006 International Conference on Mechatronics and Automation. Luoyang: IEEE Computer Society Press; 2006. p. 25-30. https://doi.org/10.1109//CMA.2006.257429.

3. Lee D-W, Lee T-G, So B, Choi M, Shin E-C, Yang K, Baek M-H, Kim H-S, Lee H-G. Development of an android for emotional expression and human interaction. In: IFAC'08 SEOUL, editor. 17th IFAC World Congress. Seoul: IFAC'08 SEOUL; 2008. p. 4336-4337. http://folk.ntnu.no/skoge/prost/ proceedings/ifac2008/data/papers/2566.pdf.

4. Lin C-Y, Cheng L-C, Tseng C-K, Gu H-Y, Chung K-L, Fahn C-S, Lu K-J, Chang C-C. A face robot for autonomous simplified musical notation reading and singing. Robot Auton Syst. 2011;59(11):943-53. https://doi.org/10. 1016/j.robot.2011.07.001.

5. Lin C-C, Huang C-C, Cheng L-C. An expressional simplified mechanism in anthropomorphic face robot design. Robotica. 2016;34(3):652-70. https://doi.org/10.1017/S0263574714001787.

6. Asheber WT, Lin C-Y, Yen SH. Humanoid head face mechanism with expandable facial expressions. Int J Adv Robot Syst. 2016;13(1):1-8. https://doi.org/10.5772/62181.

7. Hwang HY. Piezoelectric particle-reinforced polyurethane for tactile sensing robot skin. Mech Compos Mater. 2011;47(1):137-44. https://doi.org/ 10.1007/s11029-011-9192-z.

8. Dabrowska AK, Rotaru G-M, Derler S, Spano F, Camenzind M, Annaheim S, Stämpfli R, Schmid M, Rossi RM. Materials used to simulate physical properties of human skin. Skin Res Technol. 2016;22:3-14. https://doi.org/ 10.1111/srt.12235.

9. de Groot S, Lagana A, van Oosten T, van Keulen H, Palmeira M. The wear and tear of polyurethane elastomers. Investigation into properties, degradation and treatments. In: Bechthold T, editor. Future Talks 011: Technology and Conservation of Modern Materials in Design. Munich: Die Neue Sammlung; 2013. p. 89-97.

10. Xie F, Zhang T, Bryant P, Kurusingal V, Colwell JM, Laycock B. Degradation and stabilization of polyurethane elastomers. Prog Polym Sci. 2019:90:211-68. https://doi.org/10.1016/.jprogpolymsci.2018.12.003.

11. NIIR Board of Consultants \& Engineers. The Complete Book of Resins (Alkyd, Amino, Phenolic, Polyurethane, Epoxy, Silicone, Acrylic), Paints, Varnishes, Pigments \& Additives. (Surface Coating Products with Formulae). 3rd ed. India: Asia Pacific Business Press Inc.; 2018.

12. Shashoua Y. Inhibiting the inevitable; current approaches to slowing the deterioration of plastics. Macromol Symp. 2006;238:67-77. https://doi. org/10.1002/masy.200650610.

13. De Sa SF, Ferreira JL, Cardoso IP, Macedo R, Ramos AM. Shedding new light on polyurethane degradation: assessing foams condition in design objects. Polym Degrad Stabil. 2017;144:354-65. https://doi.org/10.1016/j. polymdegradstab.2017.08.028.

14. van Oosten T. PUR facts: conservation of polyurethane foam in art and design. Amsterdam: AUP Popular Science; 2011.

15. Mitchell G, France F, Nordon A, Leung Tang P, Gibson LT. Assessment of historical polymers using attenuated total reflectance-Fourier transform infrared spectroscopy with principal component analysis. Herit Sci. 2013;1:28. https://doi.org/10.1186/2050-7445-1-28.

16. Beerkens L, Supply S, Bechthold T. Matti Suuronen's `Futuro` - prototype, 1968. Back in business in the 21th century. In: Bechthold T, editor. Future Talks 015: Processes. The Making of Design and Modern Art. Materials, Technologies and Conservation Strategies. Munich: Die Neue Sammlung; 2017. p. 129-137.

17. La Nasa J, Biale G, Ferriani B, Colombini MP, Modugno F. A pyrolysis approach for characterizing and assessing degradation of polyurethane 
foam in cultural heritage objects. J Anal Appl Pyrolysis. 2018;134:562-72. https://doi.org/10.1016/j.jaap.2018.08.004.

18. La Nasa J, Biale G, Sabatini F, Degano I, Colombini MP, Modugno F. Synthetic materials in art: a new comprehensive approach for the characterization of multi-material artworks by analytical pyrolysis. Herit Sci. 2019;7:8. https://doi.org/10.1186/s40494-019-0251-4

19. Rosu D, Rosu L, Cascaval CN. IR-change and yellowing of polyurethane as a result of UV irradiation. Polym Degrad Stabil. 2009;94(4):591-6. https:// doi.org/10.1016/j.polymdegradstab.2009.01.013.

20. Somarathna HMCC, Raman SN, Mohotti D, Mutalib AA, Badri KH. The use of polyurethane for structural and infrastructural engineering applications: a state-of-the-art review. Constr Build Mater. 2018;190:995-1014. https://doi.org/10.1016/j.conbuildmat.2018.09.166.

21. Lattuati-Derieux A, Thao-Heu S, Lavédrine B. Assessment of the degradation of polyurethane foams after artificial and natural ageing by using pyrolysis-gas chromatography/mass spectrometry and headspace-solid phase microextraction-gas chromatography/mass spectrometry. J Chromatogr A. 2011;1218(28):4498-508. https://doi.org/10.1016/j.chroma. 2011.05.013.

22. Capanna F, De Cesare G, Miracola P, Sidoti G. Stage Evidence 2002 (Fotocopiatrice) Ricerche per il Restauro di una Gomma Poliuretanica. In: Rullo D, editor. Lo stato dell'arte 7: VII Congresso nazionale IGIIC. Firenze: Nardini; 2009. p. 3-12.

23. Lazzari M, Ledo-Suárez A, López T, Scalarone D, López-Quintela MA. Plastic matters: an analytical procedure to evaluate the degradability of contemporary works of art. Anal Bioanal Chem. 2011;399(9):2939-48. https://doi.org/10.1007/s00216-011-4664-5.

24. Hashimoto T, Kobayashi H, Kato N. Educational system with the android robot SAYA and field trial. In: Lin C-T, editor. 2011 IEEE International Conference on Fuzzy Systems (FUZZ). Taipei: Piscataway, NJ IEEE 2011; 2011. p. 766-771. https://doi.org/10.1109/FUZZY.2011.6007430

25. Oleari C. Standard colorimetry: definitions, algorithms and software. Hoboken: Wiley; 2016

26. McLaren K. XIII-The development of the CIE $1976\left(L^{*} a^{*} b^{*}\right)$ uniform-colour space and colour difference formula. J Soc Dye Colour. 1976;92:338-434. https://doi.org/10.1111/j.1478-4408.1976.tb03301.x.

27. Tsuge S, Ohtani H, Watanabe C. Pyrolysis-GC/MS data book of synthetic polymers. Pyrograms, thermograms and MS of pyrolyzates. The Netherlands: Elsevier; 2011.

28. FrontierLab. Multi-functional Pyrolyzer ${ }^{\circledR}$ Technical Note. Operational Principle of MicroJet Cryo Trap (MJY-1030E). 2021. https://www.frontierlab.com/assets/file/technical-note/PYT-019E.pdf. Accessed 22 Apr 2021.

29. Izzo F, Ferriani B, Annicchiarico S, Biocca P, van Keulen H, Zendri E. The use of polyurethane foam in contemporary Italian design: Case studies from the Triennale Design Museum in Milan. In: Bechthold T, editor. Future talks 013: technology and conservation of modern materials in design. Munich: Die Neue Sammlung; 2015. p. 129-37.

30. Nicolaus K. Handbuch der Gemälderestaurierung. Köln: Könemann Verlagsgesellschaft; 1998.

31. Pataki A. Remoistenable tissue preparation and its practical aspects. Restaurator. 2009;30:51-69. https://doi.org/10.1515/rest.004.

32. Pataki-Hundt A, Walter C. Comparison of lightweight Japanese tissues for overall stabilization of documents damaged by iron gall ink corrosion and an alternative to silk screen frames. Restaurator. 2018;39(2):109-27. https://doi.org/10.1515/res-2018-0007.

33. Hansen A, Lippert T, Russo A. Restauro di due maschere in lattice facenti parte l'opera d'arte "Uncolor becomes alter ego \#2" di Haim Steinbach. In: Rullo D, editor. Lo Stato dell'Arte: XIV Congresso Nazionale IGIIC. Firenze: Nardini; 2016. p. 141-6.

34. Böhme N, Anders M, Reichelt T, Schuhmann K, Bridarolli A, Chevalier A. New treatments for canvas consolidation and conservation. Herit Sci. 2020;8:16. https://doi.org/10.1186/s40494-020-0362-y.

35. Kremer 2020. Information on synthetic resin dispersions. https://www. kremer-pigmente.com/media/pdf/75000-76806uebersicht.pdf. Accessed 08 Nov 2020.

36. Kremer 2020: Information on polyurethane-dispersion 52. https://www. kremer-pigmente.com/media/pdf/76805.pdf. Accessed 29 Nov 2020.

37. Wilhelm C, Rivaton A, Gardette J-L. Infrared analysis of the photochemical behavior of segmented polyurethanes: 3 Aromatic diisocyanate based polymers. Polymer. 1998;39:1221-32. https://doi.org/10.1016/S00323861(97)00353-4.
38. Davies P, Evrard G. Accelerated ageing of polyurethanes for marine applications. Polym Degrad Stabil. 2007;92(8):1455-64. https://doi.org/10. 1016/j.polymdegradstab.2007.05.016.

39. Shashoua Y. Conservation of plastics. Materials science, degradation and preservation. Oxford: $\mathrm{BH} ; 2008$.

40. Balcar N, Lattuati-Derieux A, Vila A. Appendix 3: analysis of degradation products found during surveys of three French collections. In: Lavédrine B, Fourbier A, Martin G, editors. Preservation of plastic artefacts in museum collections. Paris: Comité Des Travaux Historiques Et Scientifiques; 2012. p. 302-8.

41. Porto $\mathrm{S}$, Fleury PA, Damen TC. Raman Spectra of $\mathrm{TiO}_{2}, \mathrm{MgF}_{2}, \mathrm{ZnF}_{2}, \mathrm{FeF}_{2}$ and $\mathrm{MnF}_{2}$. Phys Rev. 1967;154(2):522-6. https://doi.org/10.1103/PhysRev. 154.522.

42. Ohsaka T, Izumi F, Fujiki Y. Raman spectrum of anatase, $\mathrm{TiO}_{2}$. J Raman Spectrosc. 1978;7:321-4. https://doi.org/10.1002/jrs.1250070606.

43. Balachandran U, Eror NG. Raman Spectra of titanium dioxide. J Solid State Chem. 1982;42(3):276-82. https://doi.org/10.1016/0022-4596(82)90006-8.

44. Ma HL, Yang JY, Dai Y, Zhang YB, Lu B, Ma GH. Raman study of phase transformation of $\mathrm{TiO}_{2}$ rutile single crystal irradiated by infrared femtosecond laser. Appl Surf Sci. 2007;253(18):7497-500. https://doi.org/10.1016/j. apsusc.2007.03.047.

45. Vielee RC, Haney TV. Polyurethanes. In: Webber TG, editor. Coloring of plastics. New York: Wiley; 1979. p. 191-204.

46. Pappas SP, Fischer RM. Photo-chemistry of pigments: studies on the mechanism of chalking. J Paint Technol. 1974;46(599):65-72.

47. Allen NS. Photofading and light stability of dyed and pigmented polymers. Polym Degrad Stabil. 1994;44(3):357-74. https://doi.org/10.1016/ 0141-3910(94)90095-7.

48. Allen NS, Katami H. Comparison of various thermal and photoageing conditions on the oxidation of titanium dioxide pigmented linear low density polyethylene films. Polym Degrad Stabil. 1996;52:311-20. https:// doi.org/10.1016/0141-3910\%2896\%2900031-6.

49. Cho S, Choi W. Solid-phase photocatalytic degradation of $\mathrm{PVC}^{-\mathrm{TiO}_{2}}$ polymer composites. J Photochem Photobiol A: Chem. 2001;143(2-3):221-8. https://doi.org/10.1016/\$1010-6030(01)00499-3.

50. Worsley DA, Searle JR. Photoactivity test for $\mathrm{TiO}_{2}$ pigment photocatalysed polymer degradation. Mater Sci Technol. 2002;18(6):681-4. https://doi. org/10.1179/026708302225003541

51. Jin CQ, Christensen PA, Egerton TA, White JR. Rapid measurement of photocatalytic oxidation of poly(vinyl chloride) by in situ FTIR spectrometry of evolved $\mathrm{CO}_{2}$. Mater Sci Technol. 2006;22(8):908-14. https://doi.org/10. 1179/174328406X91159.

52. Holtzen DA, Reid AH. Titanium dioxide pigments. In: Charvat RA, editor. Coloring of plastics. 2nd ed. New Jersey: Wiley; 2004. p. 146-58.

53. Chen XD, Wang Z, Liao ZF, Mai YL, Zhang MQ. Roles of anatase and rutile $\mathrm{TiO}_{2}$ nanoparticles in photo-oxidation of polyurethane. Polym Test. 2007;26(2):202-8. https://doi.org/10.1016/j.polymertesting.2006.10.002.

54. EXSEAL 2020, security data sheet of pigment skin. http://www.exseal.jp/ user_data/pdf/330002pigment-skin.pdf. Accessed 29 Apr 2020.

55. Szycher M. Szycher's handbook of polyurethanes. 2nd ed. New York: CRC Press; 2013

56. Hummel DO, Scholl F. Atlas of polymers and plastics analysis. Munich: Hanser; 1990

57. Lobo H, Bonilla JV. Handbook of plastics analysis. New York: Marcel Dekker; 2003.

58. Silverstein RM, Webster FX, Klemie DJ. Spectrometric identification of organic compounds. 7th ed. New York: Wiley; 2005.

59. Romanova V, Begishev V, Karmanov V, Kondyurin A, Maitz MF. Fourier transform Raman and Fourier transform infrared spectra of crosslinked polyurethane urea films synthetized from solutions. J Raman Spectrosc. 2002;33:769-77. https://doi.org/10.1002/jrs.914.

60. Saviello D, Toniolo L, Goidanich S, Casadio F. Non-invasive identification of plastic materials in museum collections with portable FTIR reflectance spectroscopy: reference database and practical applications. Microchem J. 2016;124:868-77. https://doi.org/10.1016/j.microc.2015.07.016.

61. Tabb DL, Koenig JL. Fourier transform infrared study of plasticized and unplasticized poly(vinyl chloride). Macromolecules. 1975;8(6):929-34. https://doi.org/10.1021/ma60048a043.

62. Lavédrine B, Fournier A, Martin G. Preservation of plastic artefacts in museum collections. Paris: Comité Des Travaux Historiques Et Scientifiques; 2012. 
63. Dubelley F, Bas C, Planes E, Pons E, Yrieix B, Flandin L. Durability of polymer metal multilayer: focus on the adhesive chemical degradation. Front Chem. 2018;6:459. https://doi.org/10.3389/fchem.2018.00459.

64. Skeist I. Handbook of adhesives. 3rd ed. NY: Van Nostrand Reinhold; 1990.

65. Pocius A. Adhesion and adhesive technology — an introduction. Munich: Hanser; 1997.

66. Correia CB, Bordado JC. Synthesis and characterization of new polyurethane adhesives. In: Vilarinho PM, editor. Materials science forum. Vol. 514. Aedermannsdorf: Trans Tech Publications; 2006, 834-847. https://doi.org/ 10.4028/www.scientific.net/MSF.514-516.843.

67. Maruyama F, Fujimaki S, Sakamoto Y, Kudo Y, Miyagawa H. Screening of phthalates in polymer materials by pyrolysis GC/MS. Anal Sci. 2015;31(1):3-5. https://doi.org/10.2116/analsci.31.3.

68. Kim JW, Kim Y-M, Moon HM, Hosaka A, Watanabe C, Teramae N, Choe EK, Myung S-W. Comparative study of thermal desorption and solvent extraction-gas chromatography-mass spectrometric analysis for the quantification of phthalates in polymers. J Chromatogr A. 2016;1451:3340. https://doi.org/10.1016/j.chroma.2016.05.014

69. Neumann GM, Cullis PG, Derrick PJ. Mass spectrometry of polymers: polypropylene glycol. Z Naturforsch A. 1980;35(1):1090-7. https://doi.org/ 10.1515/zna-1980-1015.

70. Allan D, Daly J, Liggat JJ. Thermal volatilisation analysis of TDI-based flexible polyurethane foam. Polym Degrad Stab. 2013;98(2):535-41. https:// doi.org/10.1016/j.polymdegradstab.2012.12.002.

71. Wei X-F, Linde E, Hedenqvist MS. Plasticiser loss from plastic or rubber products through diffusion and evaporation. NPJ Mater Degrad. 2019:3(1):1-8. https://doi.org/10.1038/s41529-019-0080-7.

72. Stringer R, Labunska I, Santillo D, Johnston P, Siddorn J, Stephenson A. Concentrations of phthalate esters and identification of other additives in PVC children's toys. Environ Sci Pollut R. 2000;7:27-36. https://doi.org/10. 1065/espr199910.007.

73. Royaux A, Fabre-Francke I, Balcar N, Barabant G, Bollard C, Lavédrine B, Cantin S. Aging of plasticized polyvinyl chloride in heritage collections: the impact of conditioning and cleaning treatments. Polym Degrad Stabil. 2017;37:109-21. https://doi.org/10.1016/j.polymdegradstab.2017. 01.011.

74. Oberbach K, Baur E, Brinkmann S, Schmachtenberg E. Saechling Kunststoff Taschenbuch. 29th ed. Munich: Hanser; 2004.

75. Sargent M, Koenig JL, Maecker NL. FT-IR analysis of the photo-oxidation of styrene-acrylonitrile copolymers. Polym Degrad Stabil. 1993;39(3):35566. https://doi.org/10.1016/0141-3910(93)90011-7.

76. Davis $P$, Tiganis BE, Burn LS. The effect of photo-oxidative degradation on fracture in ABS pipe resin. Polym Degrad Stabil. 2004;84(2):232-42. https://doi.org/10.1016/j.polymdegradstab.2003.10.017.

77. Murphy J. Additives for plastics handbook. 2nd ed. Oxford: Elsevier Science; 2001

78. Pritchard G. Plastics additives —an A-Z reference. London: Chapman \& Hall; 1998.

\section{Publisher's Note}

Springer Nature remains neutral with regard to jurisdictional claims in published maps and institutional affiliations.

\section{Submit your manuscript to a SpringerOpen ${ }^{\circ}$ journal and benefit from:}

- Convenient online submission

- Rigorous peer review

- Open access: articles freely available online

- High visibility within the field

- Retaining the copyright to your article

Submit your next manuscript at $\boldsymbol{\nabla}$ springeropen.com 